\title{
ӘInternal Bore Evolution across the Shelf near Pt. Sal, California, Interpreted as a Gravity Current
}

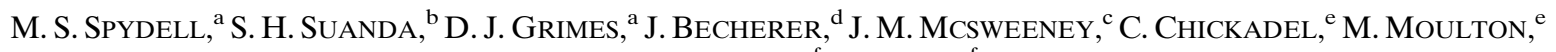 \\ J. ThOMSON,${ }^{\text {e J. LERCZAK, }}{ }^{\mathrm{c}}$ J. BARTH,${ }^{\mathrm{c}}$ J. MACMAHAN,${ }^{\mathrm{f}} \mathrm{J}$. COLOSI,${ }^{\mathrm{f}}{ }^{\mathrm{R}}$ R. ROMEISER,${ }^{\mathrm{g}}$ A. F. WATERHOUSE, ${ }^{\mathrm{a}}$ \\ J. CALANTONI, ${ }^{\mathrm{h}}$ AND FALK FEDDERSEN ${ }^{\mathrm{a}}$ \\ ${ }^{\text {a }}$ Scripps Institution of Oceanography, University of California, San Diego, La Jolla, California \\ ${ }^{\mathrm{b}}$ Department of Physics and Physical Oceanography, University of North Carolina Wilmington, Wilmington, North Carolina \\ ${ }^{\mathrm{c}}$ Oregon State University, Corvallis, Oregon \\ ${ }^{\mathrm{d}}$ Helmholtz-Zentrum Hereon, Institute of Coastal Research, Geesthacht, Germany \\ ${ }^{\mathrm{e}}$ Applied Physics Laboratory, University of Washington, Seattle, Washington \\ ${ }_{\mathrm{f}}^{\mathrm{f}}$ Naval Post Graduate School, Monterey, California \\ ${ }^{\mathrm{g}}$ Rosenstiel School of Marine and Atmospheric Science, University of Miami, Miami, Florida \\ ${ }^{\text {h }}$ Ocean Sciences Division, U.S. Naval Research Laboratory, Stennis Space Center, Mississippi
}

(Manuscript received 4 May 2021, in final form 7 October 2021)

\begin{abstract}
Off the central California coast near Pt. Sal, a large-amplitude internal bore was observed for $20 \mathrm{~h}$ over $10 \mathrm{~km}$ cross shore, or 100-10-m water depth $(D)$, and $30 \mathrm{~km}$ along coast by remote sensing, 39 in situ moorings, ship surveys, and drifters. The bore is associated with steep isotherm displacements representing a significant fraction of $D$. Observations were used to estimate bore arrival time $t_{B}$, thickness $h$, and bore and nonbore (ambient) temperature difference $\Delta T$, leading to reduced gravity $g^{\prime}$. Bore speeds $c$, estimated from mapped $t_{B}$, varied from 0.25 to $0.1 \mathrm{~m} \mathrm{~s}^{-1}$ from $D=50$ to $10 \mathrm{~m}$. The $h$ varied from 5 to $35 \mathrm{~m}$, generally decreased with $D$, and varied regionally along isobath. The bore $\Delta T$ varied from $0.75^{\circ}$ to $2.15^{\circ} \mathrm{C}$. Bore evolution was interpreted from the perspective of a two-layer gravity current. Gravity current speeds $U$, estimated from the local bore $h$ and $g^{\prime}$, compared well to observed bore speeds throughout its cross-shore propagation. Linear internal wave speeds based on various stratification estimates result in larger errors. On average bore thickness $h=$ $D / 2$, with regional variation, suggesting energy saturation. From 50- to 10 -m depths, observed bore speeds compared well to saturated gravity current speeds and energetics that depend only on water depth and shelf-wide mean $g^{\prime}$. This suggests that this internal bore is the internal wave analog to a saturated surfzone surface gravity bore. Along-coast variations in prebore stratification explain variations in bore properties. Near Pt. Sal, bore Doppler shifting by barotropic currents is observed.
\end{abstract}

KEYWORDS: Continental shelf/slope; Coastal flows; Internal waves; Density currents

\section{Introduction}

Across the continental shelf, internal waves display a range of weakly to highly nonlinear behavior as they shoal, break, and dissipate their energy (e.g., Vlasenko and Hutter 2002; Lamb 2014). These internal wave processes are important to the advective transport and vertical mixing of tracers such as plankton, heat, and sediment (e.g., Pineda 1999; Scotti and Pineda 2007; Shroyer et al. 2010b; Boegman and Stastna 2019; Becherer et al. 2021a), emphasizing their importance to coastal ecosystems (e.g., Woodson 2018). In coastal observations (e.g., Shroyer et al. 2011; Walter et al. 2012; Zhang et al. 2015; Colosi et al. 2018, hereafter C2018; McSweeney et al. 2020a, hereafter M2020a; McSweeney et al. 2020b, hereafter M2020b) and numerical models (e.g., Grimshaw et al. 2004; Helfrich and Grimshaw 2008; Aghsaee et al. 2010) internal waves manifest as a variety of features including internal solitary waves (ISW) and large-amplitude internal bores through the transformation of an offshore generated internal tide (e.g., Scotti et al. 2008;

๑ Denotes content that is immediately available upon publication as open access.

Corresponding author: Matthew Spydell, mspydell@ucsd.edu
Lamb 2014; Boegman and Stastna 2019). These features are collectively referred to as nonlinear internal waves (NLIW).

The distinction between these two NLIW forms is significant. Internal solitary waves (ISW) are often described by weakly nonlinear and dispersive dynamics of Korteweg-de Vries (KdV) theory (e.g., Helfrich and Melville 2006) that requires a small ratio of wave amplitude relative to water depth $(\ll 1)$ and similarly small ratio of water depth to wave horizontal scale (e.g., Helfrich and Melville 2006; C2018). In an idealized two-layer fluid where the upper-layer thickness is less (more) than half the water depth, this results in near surface (bottom) waves of depression (elevation). Although theoretical extensions (denoted eKdV) have been derived (e.g., Grimshaw et al. 2004), observations show KdV theory can appropriately describe observed ISW propagation and evolution (e.g., Bourgault and Kelley 2003; Shroyer et al. 2009) with departures from weakly nonlinear theory emerging for largeamplitude waves (e.g., Lamb and Yan 1996). The evolution of ISWs are modified by rotation depending on Rossby number, amplitude, and nondimensional dispersion parameter (e.g., Helfrich and Grimshaw 2008; Coutino and Stastna 2017). In contrast, internal bores on the shelf have large-amplitude (isopycnal displacements a significant fraction of the water depth), strong horizontal density gradients, and widths an order of magnitude or more longer than bore amplitude in 
observations (e.g., Scotti et al. 2008; Walter et al. 2012; C2018; Sinnett et al. 2018; M2020a) and in models (e.g., Stastna and Peltier 2005; White and Helfrich 2014), indicating nonlinear nondispersive dynamics (Helfrich and Melville 2006). For dissipative model solutions, an open ocean (3000-m depth) ISW transforms upon shoaling onto a shelf (80-m depth) with a leading edge resembling a bottom cold bore (Lamb and WarnVarnas 2015). Submesoscale horizontal density gradients can sharpen through frontogenesis and release surface bores that propagate as strongly nonlinear gravity currents in observations (Warner et al. 2018) and models (Pham and Sarkar 2018). The cross-shore evolution of an internal tidal bore may also be consistent with a gravity current.

NLIW properties such as speed, amplitude, and water column stratification are important in determining regions of energy flux convergence or divergence (e.g., Shroyer et al. 2010b; C2018) and elevated locations of shelf dissipation and mixing (e.g., MacKinnon and Gregg 2003; Becherer et al. 2021a). In coastal regions, NLIW properties of speed and direction have been extensively studied and depend on factors such as water depth, background stratification, current shear, and wave amplitude. Due to a clear surface signature, NLIWs can be measured from remote sensing with satellite, ship- or shore-based radar (e.g., Kropfli et al. 1999; Ramos et al. 2009; Celona et al. 2021), or video imagery (e.g., Pawlowicz 2003; Bourgault and Kelley 2003; Suanda et al. 2014). With a distinct arrival signal (rapid density change) in the water column interior, in situ estimates can be derived using plane wave fits to mooring arrays (e.g., Thomas et al. 2016; C2018; M2020a). Several studies combine simultaneous platforms to derive NLIW speed, direction, and amplitude following their propagation (e.g., Liu et al. 2004; Moum et al. 2007; Shroyer et al. 2010a; M2020b; Haney et al. 2021). Observed NLIWs propagate predominantly in the cross-shore direction, and NLIW studies largely focus on their cross-shore transformation. However, alongshore inhomogeneities can also be significant. For example, wave-front curvature of NLIW events in Massachusetts Bay was inferred to be due to Doppler shifting from spatially nonuniform barotropic tidal currents (da Silva and Helfrich 2008; Thomas et al. 2016), and the alongshore variation in internal bore-related kinetic energy was associated with a coastal headland (M2020b).

The shoreward evolution of nonlinear internal waves was a scientific focus of the fall (September-October) 2017 InnerShelf Dynamics Experiment (ISDE, see section 2), conducted off Pt. Sal, California (CA; Kumar et al. 2021). NLIW transformation across the shelf, alongshore variations in energy and phase, and effects on stratification have been investigated (C2018; Feddersen et al. 2020; Kumar et al. 2019; M2020a; M2020b; Becherer et al. 2021a; Haney et al. 2021). These observational studies focus on both statistical analyses of events over an experiment (C2018; M2020a; M2020b; Feddersen et al. 2020; Becherer et al. 2020, 2021a), as well as in-depth analyses of individual bore evolution centered on the well-stratified, midSeptember intensive observational period (IOP1) (M2020a; M2020b; Haney et al. 2021). A few relevant results are summarized here as they pertain to quantities investigated in this manuscript: the ratio of NLIW amplitude to water depth $(\delta)$, the speed of NLIW propagation $(c)$, the difference in horizontal and/or vertical density associated with NLIWs $(\Delta \rho)$, and NLIW energetics.

In a June-July 2015 pilot experiment to the 2017 ISDE, C2018 classified ISW and internal bores. In 50-30-m depths, observed internal bores had widths $>1 \mathrm{~km}$ and amplitude to water depth ratios ranging from $0.2<\delta<0.5$. M2020a tracked a single 2017 ISDE observed internal bore from 50- to 25 -m depth with $0.41<\delta<0.48$ (Table 3 in M2020a). In C2018, on average internal bores contained an order of magnitude more energy than ISWs, which had smaller amplitudes $(0.06<$ $\delta<0.25)$ and smaller $(\approx 100 \mathrm{~m})$ widths. Thus, strongly nonlinear internal bores dominate the energetics of NLIWs in this location. In this region, M2020b observed coherent bores over $30 \mathrm{~km}$ in the alongshore with the alongshore bore coherence decreasing as bores propagated into shallow water.

Internal bore propagation speed $c$ and its dependencies, such as background stratification, have also been investigated. In C2018, the observed internal bore propagation speed $c$ varied from 0.10 to $0.35 \mathrm{~m} \mathrm{~s}^{-1}$ in $40-\mathrm{m}$ depth. C2018 showed that a subtidally averaged stratification-based linear mode- 1 speed $c_{0}$, with KdV-based amplitude adjustment (see section 5a), better reproduced the observed $c$ for slower internal bores than for internal bores with faster propagation speeds. Over approximately 3 months of observations and $\approx 100$ bores, linear wave speeds $c_{0}$ based on time-averaged sorted stratification, compared reasonably well to observed $c$ in 40-50-m depths, with the time-dependent $c$ generally following low-frequency (subtidal) $c_{0}$ as stratification varied (M2020a). These results suggest linear or weakly nonlinear wave propagation. In M2020a, $c$ was generally slower than linear nonrotating phase speed offshore of 32-m depths, and did not decrease as rapidly in shallower water depth $D$ as would be predicted by linear speeds derived from stratification. Despite the general consistency between bore and linear wave speeds in 40-50-m depth, Eulerian ADCP velocities $\left(u_{e}\right)$ associated with the bore were similar to the bore speed $c$ (M2020a; M2020b; Haney et al. 2021) suggesting strong nonlinearity. Note that large $u_{e} / c$ ratios approaching 1 , as with modeled trapped-core, strongly nonlinear solitary waves (Lamb and Wilkie 2004; Stastna and Peltier 2005), or shoaling and dissipating shelf bottom cold bores (Lamb and Warn-Varnas 2015), are not consistent with weakly nonlinear theories ( $\mathrm{KdV}$ and $\mathrm{eKdV})$.

The cross-shelf evolution of ISWs and internal bore energetics have been previously studied statistically in $\leq 100-\mathrm{m}$ depth at Pt. Sal (C2018; M2020b; Becherer et al. 2021a; Becherer et al. 2021b, hereafter B2021b), as well as other locations including the New Jersey shelf (Shroyer et al. 2010a) and the South China Sea (Duda and Rainville 2008; St. Laurent 2008). In these studies, the average energy, energy flux, and dissipation all decrease in shallower water. In analogy to the energetics and dissipation of surfzone surface gravity wave bores, B2021b developed a framework to understand how NLIW energetics depend on water depth, stratification, and incident energy flux suggesting that the inner shelf is the internal-surfzone. B2021b showed that over the inner shelf, the average evolution of NLIW was in a state of energy saturation, defined as when NLIW amplitude (and depth-integrated available potential energy) is depth limited 
(constant $\delta \approx 1 / 2$ ). In this highly dissipative environment, it is unclear what relative role vertical and horizontal water column density variations should play on internal bores.

Although the weakly nonlinear framework of $\mathrm{KdV}$ theory shows utility in describing bore evolution, an alternate perspective, particularly for large $(\delta \approx 0.5)$ internal bores, is to interpret them as gravity currents as previously done for bores observed in 7-12-m depth (Pineda 1999; Sinnett et al. 2018). For example, larval transport by internal warm bores on the inner shelf has been modeled as a gravity current (Helfrich and Pineda 2003; Scotti and Pineda 2007). Gravity currents, the horizontal propagation of fluid of one density into a fluid with a different density, where horizontal length scales are typically long relative to vertical length scales, have been extensively studied in the laboratory via lock release experiments (e.g., Benjamin 1968; Shin et al. 2004; Sutherland et al. 2013) and applied to various environmental flows (e.g., Simpson 1997). For two fluids with different densities of total depth $D$, the gravity current speed $U$ depends on a Froude number $F_{h}$ and the buoyancy difference between the two fluids $\Delta \rho$ as

$$
U=F_{h}\left(g^{\prime} h\right)^{1 / 2},
$$

where $g^{\prime}=g \Delta \rho / \rho_{0}$ is the reduced gravity and $h$ is the depth of the current or the upper-layer thickness. The Froude number $F_{h}$ takes on different forms depending on the theoretical derivation (e.g., Ungarish 2008). For an upper-layer relative thickness of $\delta=h / D$, Shin et al. (2004) derived

$$
F_{h}=(1-\delta)^{1 / 2},
$$

which explained laboratory lock-release gravity current speeds. Based on energy considerations, the maximum gravity current thickness is $h=D / 2$ (or $\delta=1 / 2$ ) corresponding to $F_{h}=2^{-1 / 2}$ (Shin et al. 2004). In contrast to weakly nonlinear wave theory where $u_{e} / c \ll 1$, the Eulerian velocity behind the gravity current nose is the propagation speed, i.e., $u_{e}=U$. Both gravity currents and large $\delta$ solitary waves have been diagnosed with fully nonlinear, nondispersive, and energy conserving wave equation (e.g., Lamb and Wan 1998), and gravity currents can be considered the long-wave limit of such dynamics with modified surface or bottom boundary condition (e.g., White and Helfrich 2008). Although internal bores on the shelf are dissipative (C2018; B2021a) — as are laboratory gravity currents-energy conserving theory provides excellent frameworks for understanding two-layer gravity currents. As gravity current concepts are often used to represent surfzone surface gravity bores (e.g., Raubenheimer et al. 1996), to further the inner shelf analogy with the surfzone (B2021b), here we interpret the onshore transformation of a single internal bore as a gravity current.

Gravity currents have been considered in various settings for which the complexities approach field conditions. For instance, the effects of gravity current propagation into a stratified fluid (e.g., Ungarish 2006; White and Helfrich 2008), or two-layer surface gravity currents propagating up a sloping bottom (e.g., Sutherland et al. 2013) have been investigated. For gravity currents propagating into a stratified ambient in the laboratory (Maxworthy et al. 2002), observed river plume (Nash et al.
2009), or modeled (White and Helfrich 2008) all indicate that as a gravity current front slows so that $U<c_{0}$, internal waves can be radiated from the front potentially inducing energy loss to the gravity current. Consistent with these concepts, (Haney et al. 2021) observed an onshore propagating internal bore during the ISDE IOP1 that split into a forward-propagating internal wave and slower warm surface bolus propagating as a gravity current that dissipated rapidly. Gravity currents under the effect of rotation, particularly flowing along boundaries, have been extensively investigated (e.g., Griffiths 1986; Lentz and Helfrich 2002). Numerically modeled lock-release gravity currents with rotation and periodic alongfront boundary conditions show that gravity currents eventually geostrophically adjust over many inertial periods (Salinas et al. 2019).

In this manuscript, we study in detail the propagation of a single warm internal bore across the inner shelf near Pt. Sal, CA, during the mid-October IOP2. This internal bore is tracked for $\approx 20 \mathrm{~h}$ across $10 \mathrm{~km}$ of cross-shelf propagation and is observed over a $30-\mathrm{km}$ extent in the alongshore. A variety of in situ and remote sensing platforms are used to observe the bore and derive bore parameters such as speed, reduced gravity, and thickness as the bore evolves across the shelf. We add to previous detailed NLIW observations from the highly stratified mid-September IOP1 (e.g., M2020b; Becherer et al. 2020; Celona et al. 2021; Haney et al. 2021) by considering this bore during the mid-October second IOP2 with reduced stratification yet large offshore semidiurnal kinetic energy (e.g., M2020b). We apply two-layer gravity current ideas to this internal bore and explore 1) whether this particular bore propagates with speeds consistent with a two-layer gravity current formulation, 2) what gravity current ideas imply for the bore energetics, and 3) what a gravity current interpretation suggests for the bore's dynamics. Instrumentation that observed the bore is introduced in section 2. The methods to estimate bore arrival times from these instruments and bore properties such as speed, reduced gravity, and thickness are explained in section 3. Bore arrival times, bore speed, reduced gravity, and bore thickness are presented in sections $4 \mathrm{a}-4 \mathrm{c}$, respectively. The relationship between bore speeds and gravity current speeds is explored in section $4 \mathrm{~d}$ and bore energetics are presented in section 4e. Results are contextualized in light of previous work associating internal bore speed to stratification metrics (section 5a), limitations of the gravity current framework are discussed (section 5b), regional variations in the results are explored (section $5 \mathrm{c}$, and the effect of barotropic velocities investigated (section $5 \mathrm{~d}$ ). The work is summarized in section 6 .

\section{Data}

The Inner-Shelf Dynamics Experiment was conducted in the coastal waters near Pt. Sal, CA, during September and October of 2017 (Kumar et al. 2021). Moorings, ship, and drifter-based in situ sampling, as well as satellite, airborne, and shore- and ship-based remote sensing, were used to investigate inner-shelf hydrodynamics in the vicinity of a coastal headland. We focus on an internal bore that was observed by many platforms on 10 October 2017. We use a subset of the total observations, 

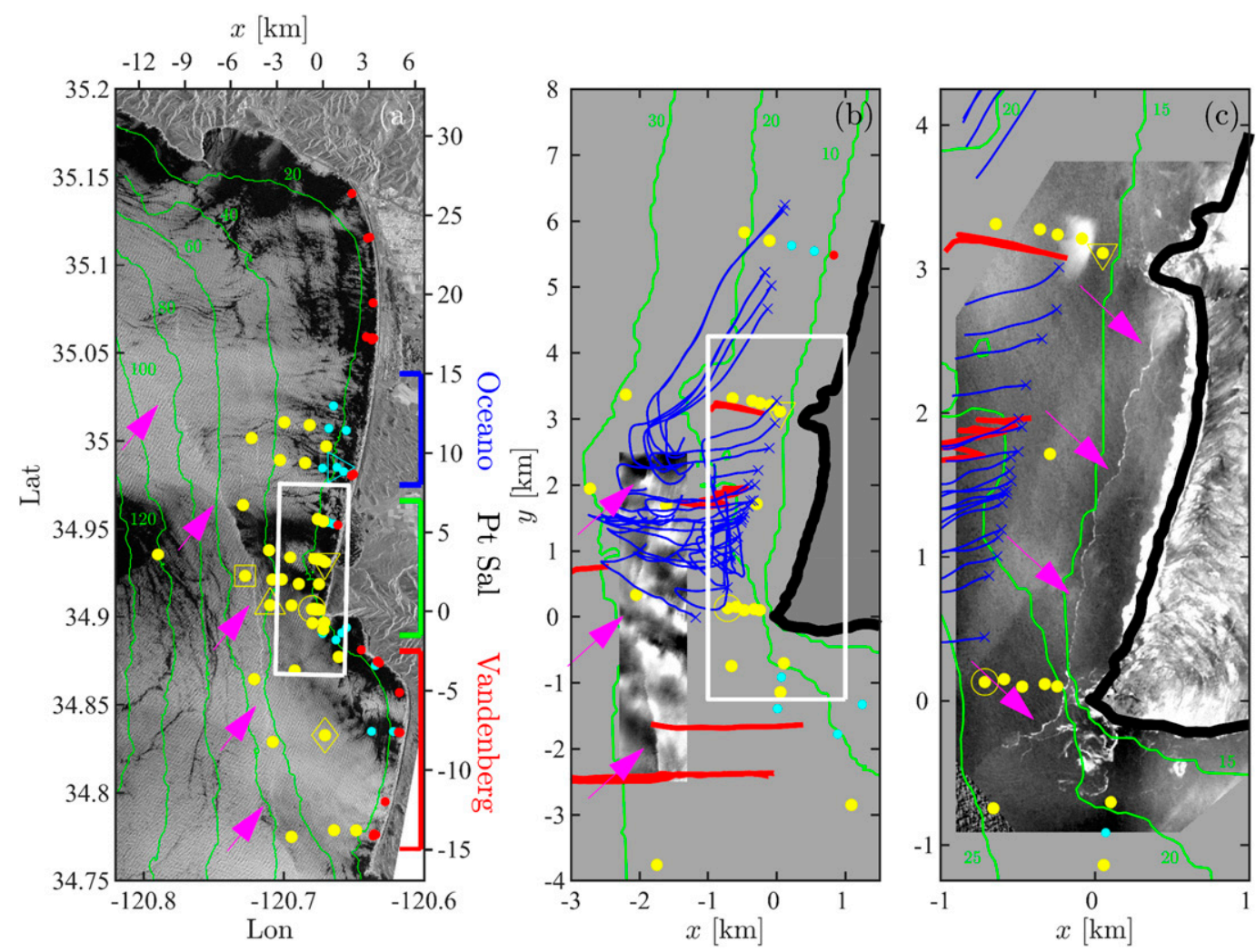

FIG. 1. Overview of the ISDE dataset at different scales: (a) satellite SAR image at 1417 UTC 10 Oct 2017 and contrast enhanced grayscale visible images taken at (b) 1815 and (c) 2330 UTC. Bathymetry (green curves) is contoured at 20-, 10-, and 5-m intervals in (a)-(c), respectively. In all panels, yellow dots indicate moorings where the bore was identified, cyan dots indicate moorings where the bore was not identified, and red dots are moorings that were too shallow to be considered (depths $\leq 10 \mathrm{~m}$ ). Temperature at the moorings indicated with open symbols (square, triangle, diamond, etc.) is discussed in the text. Pink arrows indicate the bore location in each image. In (b) and (c) drifter tracks and ship transects are indicated by blue and red curves, respectively. In (b), the entire drifter track is shown with $\mathrm{x}$ marks indicating the position just before recovery. In (c), drifter tracks for 20002100 UTC (" $x$ " at 2100 UTC) are shown. In (a), three distinct regions are indicated by colors: Oceano $(7.5<y<$ $15 \mathrm{~km}$, blue), Pt. Sal ( $-2<y<7.5 \mathrm{~km}$, green), and Vandenberg $(-15<y<-2 \mathrm{~km}$, red). The origin of the local coordinate system $(x, y)$ is the tip of Pt. Sal $\left(34.90304^{\circ} \mathrm{N}, 120.67207^{\circ} \mathrm{W}\right)$. In (a), the outline rectangle indicates the axis limits of (b), and similarly for (b) and (c).

including temperature moorings (yellow and cyan dots in Fig. 1), temperature sections from ship surveys (red lines/curves in Figs. 1b,c), GPS-tracked drifters (blue curves Figs. 1b,c), SAR (synthetic aperture radar) images (e.g., background image in Fig. 1a), and visible imagery (Figs. 1b,c). Unfortunately, due to the light winds on this day (peak winds were $6 \mathrm{~m} \mathrm{~s}^{-1}$ and mean winds were $3.1 \mathrm{~m} \mathrm{~s}^{-1}$ for 0000-2400 UTC 10 October 2017), the internal bore was not well detected by ISDE shore based radars, precluding them from this analysis. These light winds coincided with the beginning of a relaxation event where the low-frequency along coast winds that were from the north weakened, causing subtidal ocean currents to switch from southward to northward (e.g., Melton et al. 2009; Suanda et al. 2016; Feddersen et al. 2020; McSweeney et al. 2021). Throughout, local eastings $x$ and northings $y$ are the UTM projection with the origin placed at the tip of Pt. Sal: $\left(34.90304^{\circ} \mathrm{N}, 120.67207^{\circ} \mathrm{W}\right)$. Analysis will focus on three regions: Oceano, the region north of Pt. Sal and south of Pismo
Beach $(7.5<y<15 \mathrm{~km})$; Pt. Sal $(-2<y<7.5 \mathrm{~km})$; and Vandenberg, the region offshore of Vandenberg Air Force Base $(-15<y<-2 \mathrm{~km}$, see right $y$ axis in Fig. 1a).

\section{a. Moorings and ship surveys}

An array of 90 thermistor moorings were deployed near Pt. Sal, CA (red, yellow, and cyan dots Fig. 1), from 1 September 2017 through 19 October 2017 in water depths from $\approx 10$ to $100 \mathrm{~m}$. Each temperature mooring consisted of multiple thermistors with $0.5-8-\mathrm{m}$ vertical spacing (shallow moorings had higher vertical resolution) sampling at 0.5 or $1 \mathrm{~Hz}$ and a near bed $(z=-d)$ pressure sensor. Here, $z$ is the vertical coordinate with $z=0$ the mean sea surface, $d$ is the depth, and $\zeta(t)$ is the time $(t)$-dependent tidal sea surface elevation. The total water depth is then $D=d+\zeta$. Temperatures are linearly interpolated between thermistors and linearly extrapolated to the surface $(z=\zeta)$ and bottom $(z=-d)$. This results in 1-m vertically gridded temperatures spanning the entire water 
depth $D(x, y, t)$. Temperatures are low-pass filtered in time $t$ (using a Gaussian filter with a 17.5-min $e$-folding time) and then sampled at 10-min intervals. This filtering removes very highfrequency internal waves such as the ISW with 6-9-min duration observed by $\mathrm{C} 2018$. The filtered and gridded temperature at each mooring is denoted $T(t, z)$. The isotherm vertical location associated with temperature $T$ is denoted $\eta(t, T)$. Here we focus on thermistor moorings within $15 \mathrm{~km}$ of Pt. Sal $(|y| \leq 15 \mathrm{~km})$ and in water depths $d>10 \mathrm{~m}$ where the surface bore signatures are well detected. This leaves 59 moorings for analysis (yellow and cyan dots in Fig. 1). Temperature sections from ship surveys performed between 1600 and 2100 UTC 10 October 2017 by three vessels (R/V Sally Ann, R/V Sounder, and R/V Oceanus, red curves Figs. 1b,c) are also used in the analysis. Temperature sections were obtained from towyoing CTDs whose data were vertically gridded to $0.1-0.5-\mathrm{m}$ resolution and temporally gridded to 0.75-2-min intervals (approximately the time between casts). The horizontal spatial resolution depends on the vessel. During ship surveys, vessel speeds were on average $\approx 0.92 \mathrm{~m} \mathrm{~s}^{-1}$ yielding approximately 100-m spatial resolution (approximately the distance between CTD casts).

\section{b. SAR and visible images}

The 10 October bore was identified in SAR and visible imagery. Two SAR images are used in the analysis: one obtained from satellite (TerraSAR-X at 1815 UTC, Fig. 1a) and one obtained from an airplane mounted system (2034 UTC) called the Compact Airborne System for Imaging the Environment (CASIE; Farquharson et al. 2014; Shi et al. 2017). In SAR images, the bore is readily identified in the backscatter intensity as regions of increased roughness (brighter intensity near pink arrows in Fig. 1a) due to a modulation of the surface roughness via hydrodynamic wave-current interaction (Alpers 1985). This bore front is qualitatively consistent with that observed by X-band radar on 17 September (M2020b). The satellite SAR image has an initial 3-m unfiltered resolution but was processed to a pixel size of $10 \mathrm{~m} \times 10 \mathrm{~m}$ with reduced speckle noise for the analyses performed in this work. The aircraft based SAR image measures backscatter intensity at 1-m resolution with a dual-beam C-band ATI-SAR (along-track interferometric) radar.

Internal bores can be apparent in visible imagery for several reasons, including optical properties differences (e.g., color and turbidity) and the collection of bright foam at regions of converging surface currents, along with enhanced roughness and microbreaking as waves steepen in those zones. The surface front of the bore was identified in three visible images taken at 1814 (Fig. 1b), 1838, and 2330 UTC (Fig. 1c). The visible images at 1814 and 1838 UTC were taken from the CASIE system and have $5 \mathrm{~m}$ resolution. The visible image at 2330 UTC was taken with a DSLR camera through the plane window and georectified in Google Earth Pro matching coastline features resulting in an image resolution of $\approx 6.3 \mathrm{~m}$. Bright foam at the bore front is clearly visible in this image (pink arrows, Fig. 1c).

\section{c. Drifters}

There were 26 surface (top $1 \mathrm{~m}$ ) following GPS-equipped CODE drifters (Davis 1985) deployed for $\approx 6 \mathrm{~h}$ on 10 October
2017 (blue trajectories Figs. 1b,c), and they are used to track the bore front location. Drifter positions are obtained from SPOT GPS receivers that sample every $2.5 \mathrm{~min}$. Gaps are filled with interpolation and the raw positions are then filtered to 15 -min resolution with an accuracy of $\approx 4 \mathrm{~m}$, see Spydell et al. (2021) for details.

\section{Methods}

\section{a. Moored temperature bore observations}

The internal warm bore analyzed here propagated through the mooring array on 10 October 2017 as is evident in the moored temperatures $T(t, z)$ (Figs. 2a-e, note the changing times on the $x$ axis). The bore first arrived at the 100-m mooring (most offshore dot in Fig. 1a) at approximately 0850 UTC, arrived at the 50-m mooring off Pt. Sal (indicated by a square in Fig. 1a) just before 1400 UTC (Fig. 2a), and later arrived at shallower water moorings (Figs. $2 \mathrm{~b}-\mathrm{e})$. The warm bore $\left(T>15^{\circ} \mathrm{C}\right)$ is associated with rapidly descending isotherms (white and black contours). At the 50- and 40-m moorings directly west of Pt. Sal, the bore dropped the surface isotherm (black contour) approximately $1 / 2$ the water depth in $\approx 30 \mathrm{~min}$ (Figs. 2a,b). Isotherm displacements for other bores in this area are also $1 / 2$ the water depth (C2018; M2020a; Becherer et al. 2021a). At a 30-m Vandenberg mooring, the surface isotherm dropped rapidly, but not as deeply as off of Pt. Sal (Figs. 2a-c). At two moorings onshore of the 40-m mooring in the Pt. Sal region, the surface isotherms did not drop as rapidly, but the overall drop depth was also $\approx 1 / 2$ the water depth (Figs. 2 d,e). At a few moorings (cyan dots Fig. 1), the bore was not obvious. For example, at an 18-m Oceano mooring, surface isotherms did not drop substantially and the bore was not detected (see Fig. 2f).

\section{b. Mooring and ship survey bore arrival times}

An automated method was developed to find the bore arrival time $t_{B}$ from the filtered and gridded $T(t, z)$ at each mooring (e.g., Fig. 2) that is similar to M2020a. The method searches for the bore arrival within a 10-h window centered on the estimated arrival time. North of Pt. Sal, the estimated arrival time assumes an initial bore speed guess of $0.17 \mathrm{~m} \mathrm{~s}^{-1}$ propagating $15^{\circ}$ north of east (based on remote sensing of the bore, Fig. 1) passing the $40-\mathrm{m}$ mooring near Pt. Sal (triangle Fig. 1a) at 1605 UTC (Fig. 2b). South of Pt. Sal, the bore is assumed to propagate directly east as the satellite image indicates that the bore is more north-south oriented here. For this particular bore, a 10-h window ensures that bores before and after this bore are not incorrectly identified. Although bores in this region can separated by $\leq 10 \mathrm{~h}$, the average time between bores is $\geq 8 \mathrm{~h}$ in depths $50 \mathrm{~m}$ or less (M2020a), thus a 10-h window does not result in overlap with earlier or later bores. Within this 10 -h window, the isotherms $T$ that were at the surface anytime within this window are tracked. Specifically, isotherm depths $\eta(t, T)$ are tracked for surface temperatures $T$ that span from $\min \{T[t, \zeta(t)]\}$ to $\max \{T[t, \zeta(t)]\}$ at $0.05^{\circ} \mathrm{C}$ resolution over the 10 -h window centered on the estimated arrival time. Isotherms descend rapidly upon bore arrival resulting in $d \eta / d t<0$. Similar to M2020a, the surface isotherm 

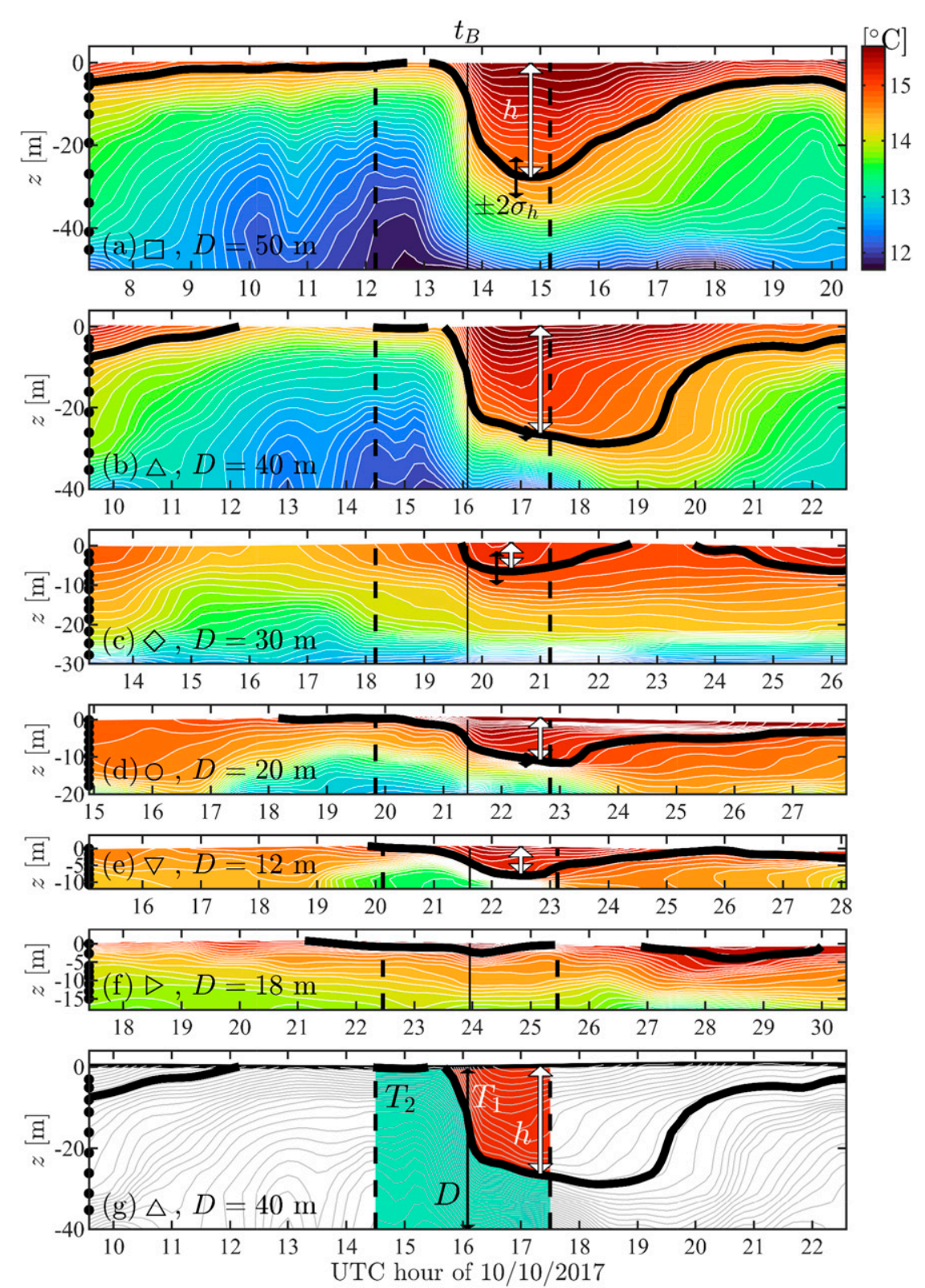

FIG. 2. (a)-(e) Low-passed (using a 17.5-min $e$-folding time Gaussian filter) temperature vs time and vertical $z$ for five moorings for which the bore was identified and (f) one mooring where the bore was not identified. Temperature is contoured at $0.1{ }^{\circ} \mathrm{C}$. Symbols in (a)-(f) correspond to moorings indicated by the same symbols in Fig. 1 . The bore arrival time $t_{B}$ is indicated by the vertical black line, and $\pm 1.5 \mathrm{~h}$ are indicated by dashed black vertical lines. The thick black contour is the bore isotherm depth $\eta_{B}$ corresponding to the bore temperature $T_{B}$ that separates bore (warm) and nonbore (cold) water. Bore thickness $h$ is indicated by the white arrows and thickness error $\pm 2 \sigma_{h}$ is indicated by black arrows. Black dots indicate thermistor locations. Note time is shifted at each mooring so that arrival time $t_{B}$ is in the center of the panel. (g) A schematic reproduction of (b) showing the bore parameters $h, D, T_{1}$, and $T_{2}$.

$T$ with the most negative $d \eta / d t$ that is at the surface within $1.5 \mathrm{~h}$ of the time of the most negative $d \eta / d t$ is defined as the bore isotherm with temperature $T_{B}$ and bore isotherm depth $\eta_{B}$ (bold isotherm in Fig. 2). The time of fastest bore isotherm descent (minimum $d \eta_{B} / d t$ ) is the bore arrival time $t_{B}$ (thin vertical black line Fig. 2). This steep isotherm descent finder is also analogous to the matched filter approach of C2018. These arrival times $t_{B}$ are very similar to the $t_{B}$ inferred using the method in M2020a. This isotherm separates warm bore water from cool prebore or ambient water and ranged from, 
(excluding the $100-\mathrm{m}$ mooring) $14.0^{\circ} \mathrm{C}$ at $40-\mathrm{m}$ depth in the $\mathrm{Pt}$. Sal region to $15.3^{\circ} \mathrm{C}$ at the shallowest moorings.

Bore arrival times are also found from 16 ship based temperature cross-shore $(x)$ transects (red tracks Figs. 1b,c). As the temperature increases rapidly offshore at the bore front, the bore arrival time $t_{B}$ from transects $T(x, z)$ is the time the ship was at the location of the minimum $d T / d x$ of the $8-\mathrm{m}$ depth temperature. This method was used rather than tracking isotherm depths as only the bore arrival time is determined from ship transects whereas bore arrival time and other bore properties (section 3e) are determined from moorings. The arrival location error is approximately the resolution, or $100 \mathrm{~m}$ in the $x$ direction as ship transects were nearly shore normal.

\section{c. Bore arrival time from images}

The bore location from SAR and visible images is obtained by manually marking the location of the bore indicator described below. These locations are then tagged with the time that the image was taken to obtain position-dependent arrival times. Although various algorithms can determine front locations from images (e.g., Simonin et al. 2009), as there are only five images here obtained from four different sources, the bore location was determined manually. For the satellite SAR, the bore indicator is the high streak of backscatter intensity (indicated by arrows in Fig. 1a). For the visible image in Fig. 1b, the bore separates a light intensity region (shoreward of the bore front) from a dark region (seaward of the bore front). For the visible image in Fig. 1c, the bore location is indicated by the obvious white foam streak angled approximately $15^{\circ}$ clockwise from north.

For the satellite SAR image (Fig. 1a), the bore location is obtained every $100 \mathrm{~m}$ between $34.74^{\circ}$ and $34.05^{\circ} \mathrm{N}$ along the high backscatter intensity ridge (for instance, near $34.95^{\circ} \mathrm{N}$ ). For most of the domain $\left(34.74^{\circ}-34.05^{\circ} \mathrm{N}\right)$, the ridge of high backscatter intensity is clear, however, in some locations the ridge it is not as obvious. In locations where the ridge is sharp the bore location is accurate to the resolution $( \pm 10 \mathrm{~m})$. In other locations, it is less accurate $( \pm 50 \mathrm{~m})$ as the ridge is diffuse. As such, overall we estimate the bore location accuracy from the satellite SAR image to be approximately $50 \mathrm{~m}$. For the CASIE SAR image, the bore location is found similarly, has similar accuracy $(50 \mathrm{~m})$ and is sampled every $50 \mathrm{~m}$ along the bore front. The bore location from the three visible images is found similarly, has similar $(50 \mathrm{~m})$ accuracy, and is sampled every $50 \mathrm{~m}$ along the bore front.

\section{d. Bore arrival time from drifters}

Drifters are used to mark the leading edge of the bore. All drifters initially move offshore before encountering the bore (Fig. 1b). The encounter is marked by large positive (onshore) drifter accelerations (drifter trajectory kinks in Fig. 1b). After encountering the bore, drifters propagate shoreward with drifters marking the bore location as drifters were observed to be in the narrow bore front region associated strong convergence that collects surface foam. For drifters that have encountered the bore, connecting drifter positions at a given time (e.g., connecting the $\mathrm{x}$ marks in Fig. 1c) approximates the continuous bore position. The bore position is obtained every
15 min between 1715 and 2130 UTC for drifters that have encountered the bore. Due to the initial cross- and alongshore distribution of drifters, the number of drifters that mark the bore location ranges from 2 to 26 depending on time.

\section{e. Bore properties}

Although stratification is continuous in the ISDE study (e.g., Fig. 2), we approximate the flow as a two-layer system so that classic two-layer gravity current scalings (1) can be applied which depend on the reduced gravity $g^{\prime}$, and the gravity current upper-layer, or bore, thickness $h$. These parameters are estimated at each mooring, except the 100-m depth mooring, using the bore isotherm $T_{B}$ and the bore isotherm depth $\eta_{B}$ associated with the mooring bore arrival time $t_{B}$. We exclude the $100-\mathrm{m}$ mooring as at this depth this event was not yet a fully developed bore, consistent with B2021b for which bores typically saturate in $D \leq 80 \mathrm{~m}$ in this region. Accurately estimating bore thickness $h$ is difficult in a laboratory setting Shin et al. (2004) and is made challenging here by other geophysical processes (e.g., wind driven surface mixing, diurnal surface heating and cooling) also present. We estimate the bore thickness $h$ from the deepest bore isotherm depth $\eta_{B}$ within $1.5 \mathrm{~h}$ of bore arrival, or $h=\zeta(t)-\min \left[\eta_{B}(t)\right]$ for $t_{B} \leq t \leq t_{B}+$ $1.5 \mathrm{~h}$. The estimated bore thickness $h$ is indicated with white arrows in Figs. 2a-g. Limiting the window to $1.5 \mathrm{~h}$ of bore arrival ensures that $h$ is associated with the bore, because at some moorings $\eta_{B}(t)$ slowly decreases in time, many hours after bore arrival (e.g., see Fig. 2b). Limiting to $1.5 \mathrm{~h}$ of bore arrival may lead to biased small bore thickness. For example, $\min \eta_{B}(t)$ is after $t_{B}+1.5 \mathrm{~h}$ in Figs. $2 \mathrm{~b}$ and $2 \mathrm{~d}$, and may introduce error into the estimate of $h$.

The temperature difference $\Delta T$ between bore (upper layer) and nonbore (lower layer) water is found from $T(t, z)$ using the bore isotherm $T_{B}$. The temperature of nonbore (lower layer) water $T_{2}$ is the depth-averaged $T(t, z)$ below $\eta_{B}$ to the bottom and averaged in time over a 3 -h window centered on $t_{B}$. Thus, $T_{2}$ is the mean of all $T(t, z)$ between the vertical dashed black lines and below the thick black curve in Fig. 2 as schematicized in Fig. $2 \mathrm{~g}$. The bore temperature $T_{1}$ is the depth-averaged $T(t, z)$ above $\eta_{B}$ to the surface $(\zeta)$ and averaged in time over a 3 -h window centered on $t_{B}$. Thus, $T_{1}$ is the mean between the vertical dashed black lines and above the thick black curve in Figs. 2a-f, as schematicized in Fig. 2g. The temperature difference between bore and nonbore water is $\Delta T=T_{1}-T_{2}$.

In the two-layer paradigm, the reduced gravity $g^{\prime}$ between bore and nonbore water is defined as

$$
g^{\prime}=g \alpha \Delta T / \rho_{0}
$$

where the thermal expansion coefficient $\alpha=0.2115 \mathrm{~kg} \mathrm{~m}^{-3}{ }^{\circ} \mathrm{C}^{-1}$ and $\rho_{0}=1025 \mathrm{~kg} \mathrm{~m}^{-3}$. Salinity variations are not included as regional observed density variations are largely due to temperature (M2020a). The thermal expansion coefficient $\alpha$ used here is based on $34.43 \mathrm{psu}$, the mean salinity during the ISDE (M2020a), and $14.75^{\circ} \mathrm{C}$, the mean bore temperature $T_{B}$.

For the bore to be considered to have arrived at a mooring, the bore must be sufficiently strong. The bore is considered weak at a mooring if the temperature change is small $\left(\Delta T<0.5^{\circ} \mathrm{C}\right)$ or 
if the isotherm displacement is small $(h<5 \mathrm{~m})$. Of the 58 moorings within total water depths $>10 \mathrm{~m}$ and alongshore distance $|y|<15 \mathrm{~km}, 4$ failed the $\Delta T$ test, 16 failed the $h$ test, and 2 failed both. Thus, at 18 moorings, the bore was not observed. For example, a bore identification failed in Fig. 2f as $h<5 \mathrm{~m}$. These moorings are excluded from the analysis (cyan dots Fig. 1). In total, the bore was identified at 40 moorings (yellow dots Fig. 1) yielding $t_{B}, T_{B}, \Delta T$, and $h$ at these moorings.

Errors in the estimated bore thickness $\sigma_{h}$ and the temperature difference $\sigma_{\Delta T}$ are estimated assuming that the isotherm $T_{B}$ used to separate bore and nonbore water may not be chosen correctly. For each mooring, a warmer and colder isotherm $T_{B} \pm 0.1^{\circ} \mathrm{C}$ is chosen resulting in a warmer and colder bore thickness $\left(h_{w}\right.$ and $\left.h_{c}\right)$ and temperature difference $\left(\Delta T_{w}\right.$ and $\left.\Delta T_{c}\right)$. We choose $0.1^{\circ} \mathrm{C}$ as this is the standard deviation of $T_{B}$ at the six 50-m moorings. The $h_{w}\left(h_{c}\right)$ are smaller (larger) than the $h$ from $T_{B}$. The error in the bore thickness $h$ is then estimated as $\sigma_{h}=\left(h_{c}-h_{w}\right) / 2$ (black arrows indicate $\pm 2 \sigma_{h}$ in Fig. 2) and the temperature difference error $\sigma_{\Delta T}=\left|\Delta T_{c}-\Delta T_{w}\right| / 2$ is similarly estimated. The variation $\sigma_{h}$ ad $\sigma_{\Delta T}$ depends on stratification details, for example, if isotherms are compressed near $T_{B}$, then $\sigma_{h}$ is small and the boundary between bore and ambient is well defined. Conversely, if the isotherms are separated near $T_{B}$, the larger $\sigma_{h}$ reflects the uncertainty in choice of $T_{B}$ and $h$.

\section{f. Mapping of bore arrival and bore velocity}

Bore arrival times $t_{B}$ from all assets (moorings, ship transects, images, and drifters) are mapped $\left(\hat{t}_{B}\right)$ to a $25-\mathrm{m}$ uniform grid between $-14 \leq x \leq 6 \mathrm{~km}$ and $-15 \leq y \leq 15 \mathrm{~km}$ using a smoothing spline (e.g., Reinsch 1967) method. This technique has been used in atmospheric (e.g., Wahba and Wendelberger 1980) and oceanographic (e.g., Trossman et al. 2011) applications. The smoothness of the resulting map can be controlled and the technique transitions between interpolation/extrapolation for low data density to regression for large data density. This is useful to this particular dataset where the data density $\left(t_{B}\right.$ from moorings) is low away from Pt. Sal but the data density $\left(t_{B}\right.$ from images, drifters, and moorings) is high near Pt. Sal. The mapped arrival times $\hat{t}_{B}(x, y)$ are found by minimizing the cost function $\Psi$ :

$$
\Psi=\frac{1}{N}\left\|t_{B}-\mathbf{R} \hat{t}_{B}\right\|^{2}+\lambda^{4} \hat{t}_{B}^{T} \mathbf{\Omega} \hat{t}_{B} .
$$

with respect to $\hat{t}_{B}$. There are $N$ arrival times $t_{B}$ from all assets and the matrix $\mathbf{R}$ is the regressor matrix using bilinear interpolants. The second term on the RHS of (4) is the penalty term controlling the smoothness. The penalty is the mean squared second derivative over the mapped domain

$$
\hat{t}_{B}^{T} \boldsymbol{\Omega} \hat{t}_{B}=\frac{1}{L_{x} L_{y}} \int_{0}^{L_{x}} \int_{0}^{L y}\left(\frac{d^{2} \hat{t}_{B}}{d x^{2}}\right)^{2}+\left(\frac{d^{2} \hat{t}_{B}}{d y^{2}}\right)^{2} d x d y .
$$

with the matrix $\boldsymbol{\Omega}$ based on finite difference estimated second derivatives and integrals estimated as a sum. Smoothness of $\hat{t}_{B}$ is determined by the penalty length scale $\lambda$. We use $\lambda=$ $700 \mathrm{~m}$ corresponding to mapped arrival time second derivatives $\left(\partial \hat{t}_{B} / \partial x^{2}\right)$ of $2 \times 10^{-6} \mathrm{~h} \mathrm{~m}^{-2}$ penalized equally to $1-\mathrm{h}$ differences between measured and mapped arrival times. For a mean bore speed $\bar{c}=0.15 \mathrm{~m} \mathrm{~s}^{-1}$, this is equivalent to penalizing gradients in $c$ larger than approximately $8 \times$ $10^{-5} \mathrm{~s}^{-1}$. For two moorings separated by $700 \mathrm{~m}$ and the same mean bore speed, this is the $d c / d x$ error that arises from 30 min arrival time errors. Thus, penalization is consistent with the approximate accuracy of the arrival times $t_{B}(\approx 30 \mathrm{~min})$. The arrival time map $\hat{t}_{B}$ (background colors of Fig. 3 ) is calculated using the arrival times from 40 moorings, 16 ship transects, 1 SAR satellite image, 1 CASIE SAR image, 3 visible images, and 26 drifters. Note that in Fig. 3, mapped arrival times (background colors), instrument arrival times (colored symbols), and image arrival times (colored lines) are all colored independently so that differences between mapped $\hat{t}_{B}$ and observed $t_{B}$ can be determined. Consistent with the estimated mooring arrival time errors and value of the smoothness parameter $\lambda$ congruent with these errors, the RMS difference between the arrival time map at the mooring locations and mooring arrival times is $30 \mathrm{~min}$. Thus, except for two moorings $<1 \mathrm{~km}$ south of Pt. Sal, background colors $\left(\hat{t}_{B}\right)$ and marker colors $\left(t_{B}\right.$, colored independently) are nearly identical in Fig. 3 indicating that mapped and observed arrival times are very similar.

Errors in the arrival time map $\sigma_{\hat{t}_{B}}$, due to errors from the instrument arrival times, are estimated by Monte Carlo simulation. A total of 400 different arrival time maps are constructed by adding errors to the instrument arrival times (for moorings) or adding error to the arrival time location (images, ship transects, and drifters). The errors are drawn from a Gaussian distribution with standard deviations based on the errors of each instrument: $30 \mathrm{~min}$ for moorings, $100 \mathrm{~m}$ for ship transects, $50 \mathrm{~m}$ for images, and $25 \mathrm{~m}$ for drifters. The standard deviation of these 400 different arrival time maps is $\sigma_{\hat{t}_{B}}(x, y)$. The error ranges from 1 to $30 \mathrm{~min}$ with small errors where there are many instruments (near Pt. Sal, e.g., Fig. 3b) and large errors at moorings on the perimeter of the domain.

Bore speed and direction are estimated from the arrival time map $\hat{t}_{B}(x, y)$ (as similarly done in Celona et al. 2021). The direction of bore propagation $\theta$ is up the gradient of $\hat{t}_{B}(x, y)$,

$$
\theta=\tan ^{-1}\left[\left(\frac{\partial \hat{t}_{B}}{\partial y}\right) /\left(\frac{\partial \hat{t}_{B}}{\partial x}\right)\right]
$$

and the bore speed $c$ is the inverse of the arrival time gradient magnitude

$$
c(x, y)=\left\|\nabla \hat{t}_{B}\right\|^{-1} .
$$

Thus, the bore velocity vector is $c(\cos \theta \mathbf{i}+\sin \theta \mathbf{j})$. Derivatives of $\hat{t}_{B}$ are estimated with finite differences on the 25 -m grid. Error in the speed map $\sigma_{c}$ is the standard deviation of the 400 speed maps corresponding to the 400 Monte Carlo simulated arrival time maps. Speed map errors range from 0.001 to $0.028 \mathrm{~m} \mathrm{~s}^{-1}$ and are smallest where there are the most instruments (near Pt. Sal, Fig. 4b) and largest at the where there are few moorings on the perimeter of the domain. As these errors are small compared to the typical speed (approximately $0.15 \mathrm{~m} \mathrm{~s}^{-1}$ ), the bore speed 

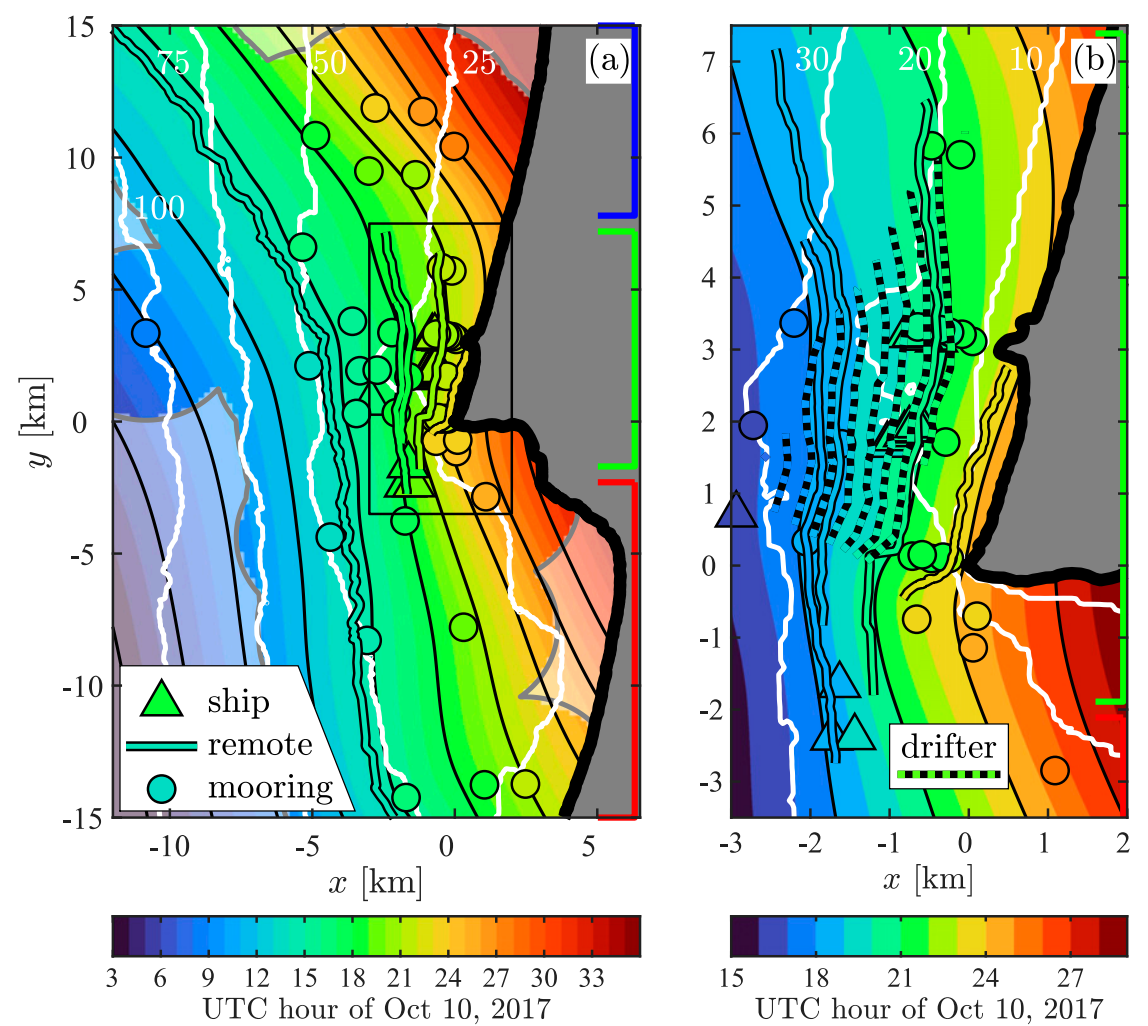

FIG. 3. The bore arrival times on the (a) large and (b) small scale as a function of $x$ and $y$. Symbols and lines are instrument arrival times $t_{B}$ : moorings (colored circles), ship transects (colored triangles), and images (black outlined colored solid curves). Background colors are the arrival time map $\hat{t}_{B}$ and are colored independently from the instrument arrival times. Black contours shown every $3 \mathrm{~h}$. In (b), the drifter derived bore locations (1730-2100 UTC every $30 \mathrm{~min}$ ) are indicated by colored dashed curves. Gray curves and transparency represent areas farther than $3300 \mathrm{~m}$ from the nearest data point in the mapping. Bathymetry intervals (white contours) are $25 \mathrm{~m}$ in (a) and $10 \mathrm{~m}$ in (b). Colors on the right axis indicate regions: Vandenberg $(y<-2 \mathrm{~km}$, red), Pt. Sal $(-2<y<7.5 \mathrm{~km}$, green $)$, and Oceano $(y>7.5 \mathrm{~km}$, blue $)$. The origin $(0,0)$ in both panels is the tip of Pt. Sal $\left(34.90304^{\circ} \mathrm{N}, 120.67207^{\circ} \mathrm{W}\right)$.

map $c$ is not very sensitive to instrument arrival times errors, especially in regions of high data density.

\section{Results}

\section{a. Bore arrival time}

Both mapped $\left(\hat{t}_{B}\right)$ and observed $\left(t_{B}\right)$ bore arrival times (Fig. 3) indicate that the bore took approximately $20 \mathrm{~h}$ to cross $\approx 15 \mathrm{~km}$ of the shelf (Fig. 3a). The bore arrived at the $100-\mathrm{m}$ mooring at 0850 UTC [blue colored circle at $(x, y) \approx(-10.5,3.5) \mathrm{km}$ in Fig. 3a] and passed the northeastmost mooring $(x, y) \approx(0$, 11) $\mathrm{km}$ at $2700 \mathrm{UTC}$, simultaneous with its passage at the mooring southeast of the Pt. Sal tip, $(x, y) \approx(1,-2) \mathrm{km}$. The satellite SAR image (1417 UTC, black outlined blue/green curve Fig. 3a) indicates that the bore was approximately at the 50-m bathymetry contour in the Vandenberg and Pt. Sal regions $(y<$ $7.5 \mathrm{~km}$ ), which is angled a few degrees CCW (counterclockwise) from north. Arrival time at the regional 50-m moorings (colored circles Fig. 3a) was within $1 \mathrm{~h}$ of the satellite SAR image time.
North of the northern end of the Pt. Sal region and throughout the Oceano region $(y>7.5 \mathrm{~km})$, the satellite SAR image indicates that the bore was angled substantially offshore $\left(\approx 30^{\circ} \mathrm{CCW}\right.$ from north), consistent with the Oceano 50-m mooring arrival times (colored circles Fig. 3a).

In the Pt. Sal region, the bore passed a ship $[(x, y) \approx(-3$, 1) $\mathrm{km}$ blue triangle Fig. 3b] at approximately 1600 UTC and then encountered the drifter array approximately $1 \mathrm{~h}$ later (most offshore blue dashed curves Fig. 3b). In this highly sampled region, bore arrival times are consistent for overlapping observations from different instrumentation. For instance, drifters and CASIE-visible imagery (dashed and solid light blue curves at $x \approx-2 \mathrm{~km}$ in Fig. $3 \mathrm{~b}$ ) show similar bore positions at 1800 UTC. Drifters and CASIE SAR imagery (dashed and solid green curves at $x \approx-1 \mathrm{~km}$ in Fig. 3b) show similar bore positions at 1800 UTC. Imagery and drifters indicate that the bore inshore of $x \approx-1.5 \mathrm{~km}$ displays a kink at $y \approx 0 \mathrm{~km}$ with the normal to the bore, for $y<0 \mathrm{~km}$, pointed toward the southeast. Arrival times south of this kink, for instance at the moorings directly south of the Pt. Sal tip, occur 


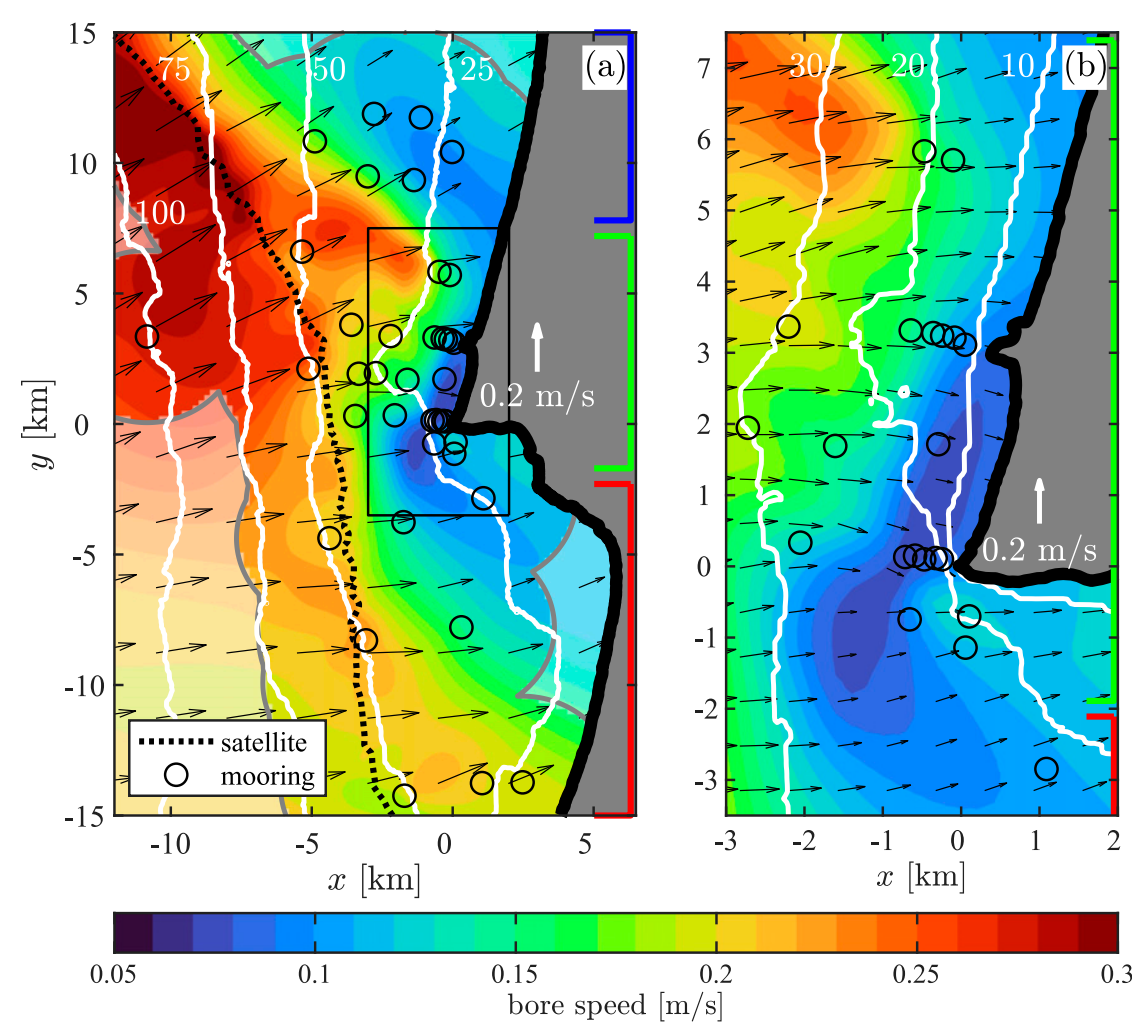

FIG. 4. The bore speed $c(x, y)$ (7) based on gradients of $\hat{t}_{B}(x, y)$ on (a) the large and (b) small scales. Arrows indicate bore direction $\theta$ and magnitude $c$. White dots indicate mooring locations and black dots in (a) indicate the satellite SAR bore location. Regions farther than $3.3 \mathrm{~km}$ from a data point (gray curve) are transparent. Bathymetry (white contours) are shown at 25- and 10-m intervals in (a) and (b), respectively. Colors on the right axis indicate regions: Vandenberg $(y<-2 \mathrm{~km}$, red), Pt. Sal $(-2<y<7.5 \mathrm{~km}$, green $)$, and Oceano $\left(y>7.5 \mathrm{~km}\right.$, blue). The origin $(0,0)$ in both panels is the tip of Pt. Sal $\left(34.90304^{\circ} \mathrm{N}\right.$, $\left.120.67207^{\circ} \mathrm{W}\right)$.

after moorings north of Pt. Sal with similar $x$ [moorings near $\approx$ $(-0.5,5.5 \mathrm{~km})]$.

\section{b. Bore speed and direction}

The bore speed $c$ (7) and propagation direction $\theta(6)$ estimated from $\hat{t}_{B}$ show significant variability over the mapped domain (Fig. 4). Bore speeds range from $\approx 0.28 \mathrm{~m} \mathrm{~s}^{-1}$ (at $100 \mathrm{~m}$ mooring) to $<0.1 \mathrm{~m} \mathrm{~s}^{-1}$ near the shoreline (Fig. 4a). Although $c$ decreases shoreward, there is significant alongshore variation as seen in other bores studied in the more stratified mid-September IOP1 (M2020b; Celona et al. 2021). Offshore of $50-\mathrm{m}$ depth, speeds are greater to the north $\left(\approx 0.28 \mathrm{~m} \mathrm{~s}^{-1}\right)$ than to the south $\left(\approx 0.2 \mathrm{~m} \mathrm{~s}^{-1}\right)$. In the Oceano region $(y \approx 12 \mathrm{~km})$, speeds slow to $\approx 0.15 \mathrm{~m} \mathrm{~s}^{-1}$ shoreward of the 50-m depth, whereas at the northern end of the Pt. Sal region $(y \approx 7 \mathrm{~km})$ high speeds $\left(\approx 0.2 \mathrm{~m} \mathrm{~s}^{-1}\right)$ extend shoreward of 25-m depths. In the Vandenberg region $(y<-2 \mathrm{~km})$, relatively high speeds $\left(\approx 0.2 \mathrm{~m} \mathrm{~s}^{-1}\right)$ extend to the shoreline. In the Pt. Sal region (Fig. $4 \mathrm{~b}$ ), speeds decrease from $\approx 0.2$ to $<0.1 \mathrm{~m} \mathrm{~s}^{-1}$ within approximately $3 \mathrm{~km}$. In the Pt. Sal region, slow speeds $\left(<0.1 \mathrm{~m} \mathrm{~s}^{-1}\right)$ are found just offshore of the shoreline extending SW off the tip of Pt. Sal. The region of slow speeds south of the Pt. Sal tip coincides with the kinks in the arrival time from drifters and images at $y=0 \mathrm{~km}$ (Fig. 3b). The bore propagation direction $\theta$ varies over the region from $-25^{\circ}$ to $+30^{\circ}$ (propagating to the east-southeast-eastnortheast, respectively). Throughout most of the domain, except close to Pt. Sal, the bore generally propagates toward the east-northeast. South of $y=0 \mathrm{~m}$ the direction is almost due east with $\theta \approx+10^{\circ}$, while north of $y=0$ the bore propagates significantly to the east-northeast, $\theta \approx+30^{\circ}$ (Fig. 4a). In the Pt. Sal region, close to shore (within $2 \mathrm{~km}$ of the shoreline), the bore directions evolve to be more shore normal such that the bore propagates to the east-southeast and $\theta=-20^{\circ}$ (Fig. 4b).

\section{c. Bore statistics}

The bore thickness $h$ (section $3 \mathrm{e}$ ) generally decreases shoreward (Fig. 5a1). Bore thickness $h$ ranges from $>30 \mathrm{~m}$ (south of Pt. Sal on the $50-\mathrm{m}$ isobath) to $\leq 10 \mathrm{~m}$ at the shallowest moorings closest to shore (Fig. 5a1). Near Pt. Sal (Fig. 5a2), $h$ noticeably decreases with depth. For all (excluding the $100 \mathrm{~m}$ ) moorings, $h$ and $D$ are linearly related with correlation $r=0.73$. The direct dependence of $h$ on $D$ is better 

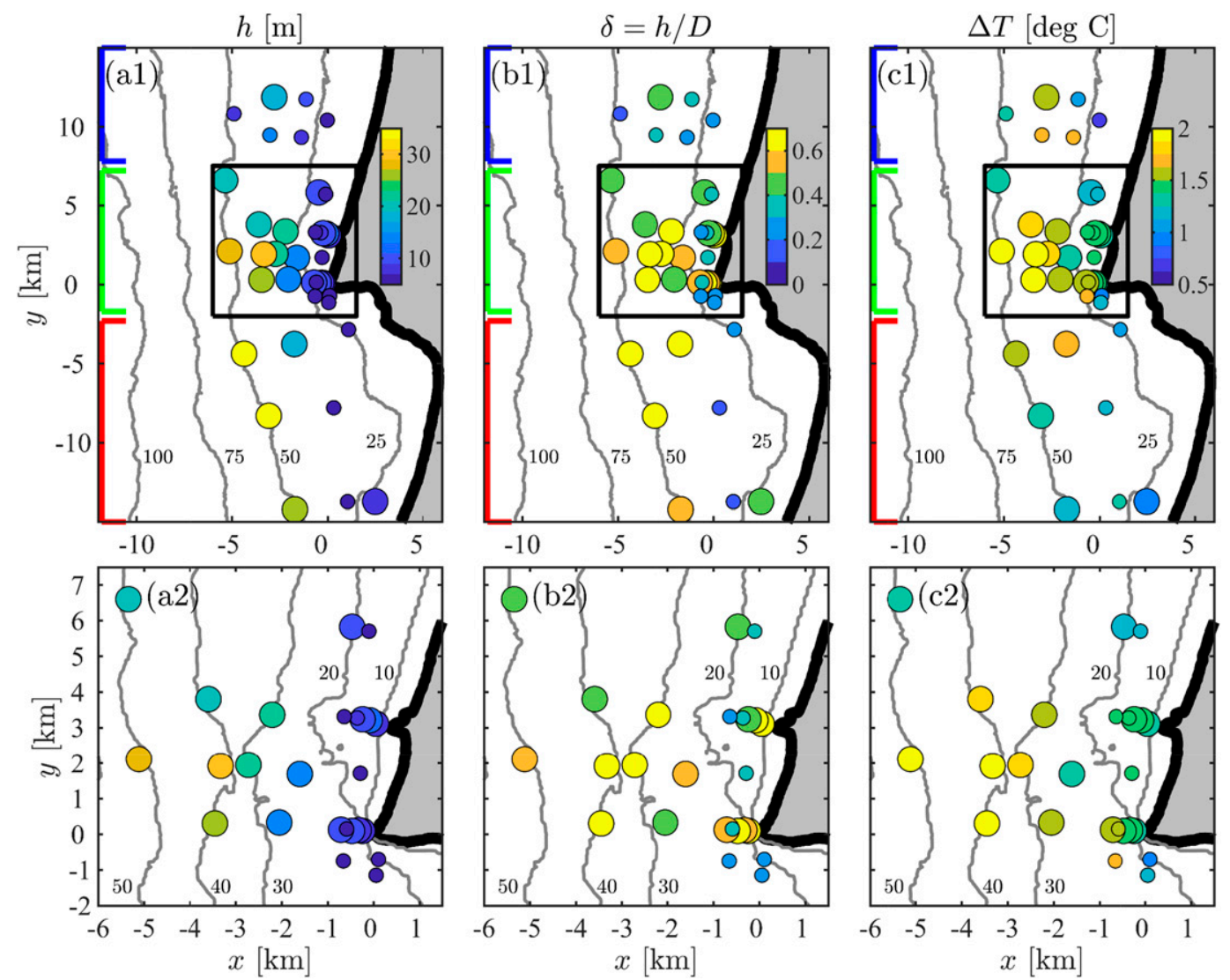

FIG. 5. The (a1) bore thickness $h$, (b1) bore relative thickness $\delta=h / D$, and (c1) temperature difference $\Delta T$ at all of the moorings where the bore was identified. (a2)-(c2) Blow ups of the Pt. Sal region indicated in (a1)-(c1) with a black rectangle. Large and small marker size corresponds to $\delta>0.4$ and $\delta<0.4$, respectively. Bathymetry (gray contours) are at 25-m intervals in (a1)-(c1) and 10-m intervals in (a2)-(c2). Colors on the left axis of (a1)-(c1) indicate regions: Vandenberg $(y<-2 \mathrm{~km}$, red), Pt. Sal $(-2<y<7.5 \mathrm{~km}$, green); and Oceano $\left(y>7.5 \mathrm{~km}\right.$, blue). The origin $(0,0)$ in all panels is the tip of Pt. Sal $\left(34.90304^{\circ} \mathrm{N}\right.$, $\left.120.67207^{\circ} \mathrm{W}\right)$.

inferred by the relative bore thickness $\delta=h / D$ that ranges from near 0 to 0.75 (Fig. 5b1). At five (of six) 50-m moorings, the bore is relatively thick with $0.4 \leq \delta \leq 0.75$ while at the 50 -m Oceano mooring $(x, y) \approx(-5,10) \mathrm{km}$ the bore is relatively thin $\delta=0.16$. Generally, $\delta$ shows no obvious depth $D$ dependence further confirming $h \sim D$. However, the relative thickness $\delta$ does have regional dependence. For instance, the majority of Pt. Sal region moorings have relatively large $\delta$ (Fig. 5b2), whereas, $\delta$ is relatively small in the Oceano region and is more variable in the Vandenberg region.

The bore temperature difference $\Delta T$ (section $3 \mathrm{e}$ ) varies from $0.75^{\circ}$ to $2.15^{\circ} \mathrm{C}$ over the region (Fig. 5c1). This corresponds to $g^{\prime}$ (3) varying from 0.0015 to $0.0044 \mathrm{~m} \mathrm{~s}^{-2}$. Like $h$, $\Delta T$ also decreases with decreasing depth (Fig. 5c1), especially in the Pt. Sal region (Fig. 5c2). However, the relationship between $D$ and $\Delta T$ is weaker than $D$ and $h$ as the correlation between $D$ and $\Delta T$ is $r=0.38$. The $\Delta T$ have a regional alongshelf gradient with the largest mooringaveraged $\Delta T=1.49^{\circ} \mathrm{C}$ (corresponding to $\overline{g^{\prime}}=0.0031 \mathrm{~m} \mathrm{~s}^{-2}$ ) in the Pt. Sal region. In the Oceano region, the average $\Delta T=$ $1.38^{\circ} \mathrm{C}\left(\overline{g^{\prime}}=0.0028 \mathrm{~m} \mathrm{~s}^{-2}\right)$ is weaker than the Pt. Sal region, and slightly larger than the mean $\Delta T$ in the Vandenberg region $=1.28^{\circ} \mathrm{C}\left(\overline{g^{\prime}}=0.0027 \mathrm{~m} \mathrm{~s}^{-2}\right)$. Thus, $\Delta T$ generally decreases north and south away from Pt. Sal.

\section{d. Parameterizing bore speed with two-layer gravity current scaling}

Two-layer gravity current speeds $U$, based on Shin et al. (2004), are determined at each mooring from $h, D$, and $\Delta T$ using (1)-(3). Errors in the gravity current speed $\sigma_{U}$ are estimated by assuming that $h$ and $\Delta T$ are independent Gaussian random variables with standard deviations $\sigma_{h}$ and $\sigma_{\Delta T}$, respectively. The resulting standard deviation of $U$ is the error $\sigma_{U}$. Both the estimated mooring bore speed $c$ (speed at circles in Fig. 4) and $U$ vary from $\approx 0.08$ to $0.25 \mathrm{~m} \mathrm{~s}^{-1}$ (Fig. 6a). The observed bore speed $c$ is predicted by $U$ (Fig. 6a) with small (relative to typical $c \sim$ $0.15 \mathrm{~m} \mathrm{~s}^{-1}$ ) mean bias $\overline{c-U}=0.010 \mathrm{~m} \mathrm{~s}^{-1}$ where the overbar represents an average over all $<100$-m moorings (Table 1 ). The scatter is quantified by the RMS error (RMSE), 

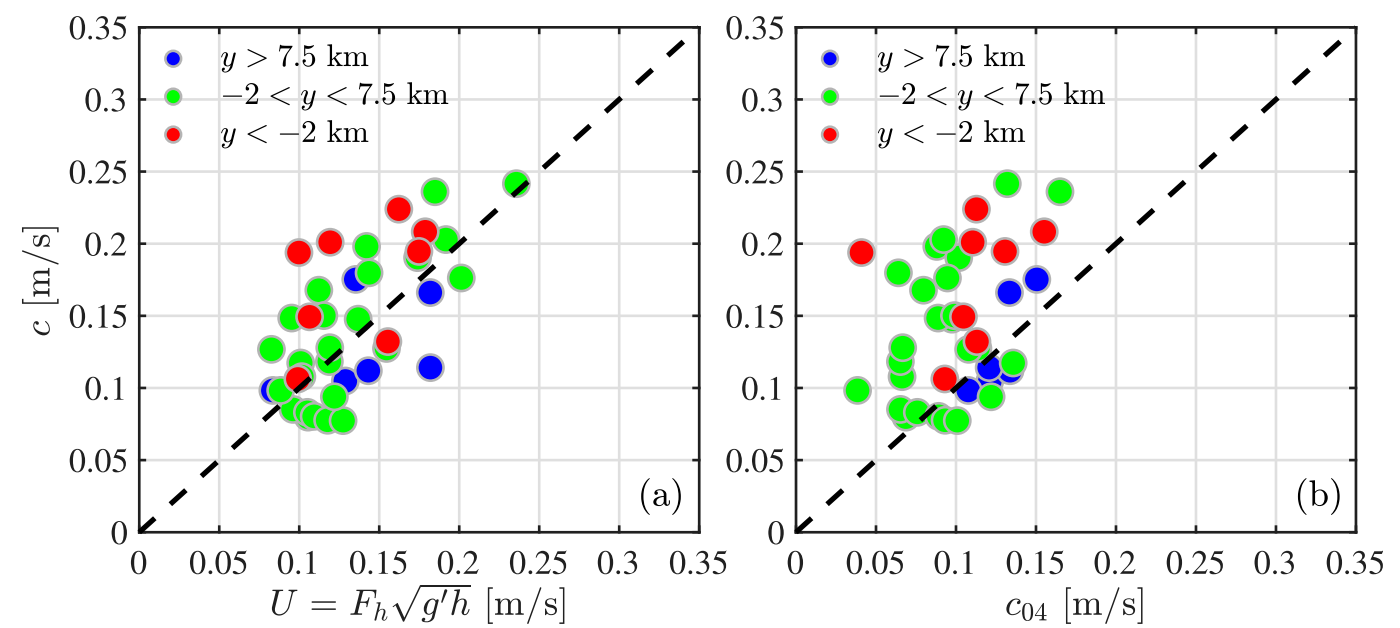

FIG. 6. Bore speed $c$ (7) at the moorings vs (a) the gravity current speed $U$ (1) and vs (b) the prebore stratification linear wave speed $c_{04}(13)$. Colors refer to region: Vandenberg $(y<-2 \mathrm{~km}$, red), Pt. Sal $(-2<y<7.5 \mathrm{~km}$, green), and Oceano $\left(y>7.5 \mathrm{~km}\right.$, blue). Dashed black line is the 1-to-1 line. Errors in the observed bore speed $\sigma_{c}$ at each mooring range from 0.001 to $0.024 \mathrm{~m} \mathrm{~s}^{-1}$, with RMS $0.009 \mathrm{~m} \mathrm{~s}^{-1}$ over all moorings, and have RMS values 0.017 , 0.006 , and $0.007 \mathrm{~m} \mathrm{~s}^{-1}$ for the Vandenberg, Pt. Sal, and Oceano region moorings, respectively. Gravity current speed errors $\sigma_{U}$ range from 0.000 to $0.023 \mathrm{~m} \mathrm{~s}^{-1}$, with RMS $0.008 \mathrm{~m} \mathrm{~s}^{-1}$ over all moorings, and have RMS values $0.013,0.006$, and $0.010 \mathrm{~m} \mathrm{~s}^{-1}$ for the Vandenberg, Pt. Sal, and Oceano moorings, respectively. Errors in $c_{04}$ are not estimated.

$\left[{\overline{(c-U)^{2}}}^{1 / 2}=0.038 \mathrm{~m} \mathrm{~s}^{-1}\right.$, and the $c-U$ correlation coefficient is $r=0.65$. The scatter as measured by the RMSE is approximately $20 \%$ of the mean $c$ (or the $c$ range). The relationship between $c$ and $U$ varies between regions and is best in the Pt. Sal region with RMSE $=0.032 \mathrm{~m} \mathrm{~s}^{-1}$ (green dots Fig. 6a). The Oceano region RMSE $=0.037 \mathrm{~m} \mathrm{~s}^{-1}$ (blue dots Fig. 6a) and in Vandenberg region the RMSE = $0.054 \mathrm{~m} \mathrm{~s}^{-1}$ is the largest (red dots Fig. 6a). The RMSE found here is significantly smaller than in C2018, particularly for larger $c$. Errors in the estimates of $c$ and $U\left(\sigma_{c}\right.$ and $\left.\sigma_{U}\right)$ are less than $0.025 \mathrm{~m} \mathrm{~s}^{-1}$ with an RMS of $\approx 0.009 \mathrm{~m} \mathrm{~s}^{-1}$. Speed errors, both $\sigma_{c}$ and $\sigma_{U}$ are largest in the Vandenberg region, the region where the RMSE between $c$ and $U$ is largest. Although the $c-U$ relationship has some scatter, their similarity indicates that the bore's speed is largely consistent with a two-layer gravity current interpretation, particularly as $c$ and $U$ are calculated independently.

Both bore speeds $c$ and parameterized gravity current speeds $U$ similarly decrease with decreasing total water depth $D$ (Fig. 7a). At similar depths, bore speeds $c$ are generally smaller in the Oceano region than Pt. Sal or Vandenberg (cf. blue to green and red dots in Fig. 7a). For all the moorings, the fractional bore depth $\delta=h / D$ ranges from 0.15 to 0.75 and has no particular $D$ dependence (Fig. $7 \mathrm{~b}$ ). Although $\delta \leq 1 / 2$ for flat bottom gravity currents, $\delta>1 / 2$ is possible for gravity currents propagating into shallower depth (Sutherland et al. 2013). The fractional bore depth $\delta$ varies geographically with generally small $\delta$ in Oceano region $(\bar{\delta}=0.28$ averaged over six regional moorings), larger $\delta$ in the Pt. Sal region $(\bar{\delta}=0.49)$, and in the Vandenberg region $\delta$ is similarly varied with regional $\bar{\delta}=0.45$ (colored lines in Fig. 7b). Thus for this bore, the
Pt. Sal and Vandenberg regions have on average $\delta \approx 1 / 2$. For a different bore during IOP1 in the Oceano region, M2020a also found $\delta$ approximately $1 / 2(0.41-0.48)$. Bores thickness that are half the water depth suggest a saturated inner shelf (B2021b).

The Froude number $F_{h}=\sqrt{1-\delta}(2)$ is critical to determining the gravity current speed (1). At all moorings, $F_{h}$ ranges from 0.5 to 0.92 (open circles Fig. 7c), shows no dependence on total depth $D$ overall, and has a mooring averaged $\bar{F}_{h}=0.73$ (dashed black line Fig. 7c) corresponding to $\bar{\delta}=1-\bar{F}_{h}^{2}=0.47$ (black dashed line Fig. 7b). The Oceano region averaged $\bar{F}_{h}=0.85$ is larger than in the other regions with averaged $\bar{F}_{h}=0.70$ and $\bar{F}_{h}=0.73$, respectively in the Pt. Sal and Vandenberg regions (colors in Fig. 7c).

The gravity current speed dependence on total depth $D$ is estimated using the mooring (except $100 \mathrm{~m}$ ) averaged reduced gravity $\overline{g^{\prime}}=0.0030 \mathrm{~m} \mathrm{~s}^{-2}$ and $\bar{F}_{h}=0.73$ (i.e., $\bar{\delta} \approx 1 / 2$ ) substituted into (1),

$$
\bar{U}_{D}=\bar{F}_{h}\left(1-\bar{F}_{h}^{2}\right)^{1 / 2} \sqrt{\overline{g^{\prime}} D},
$$

that only depends on $D$. The mean gravity current speed $\bar{U}_{D}$ passes through the cluster of estimated bore speeds $c$ (cf. dashed black curve and colored dots Fig. 7a). The $c-\bar{U}_{D}$ bias is $0.00004 \mathrm{~m} \mathrm{~s}^{-1}, \mathrm{RMSE}$ is $0.033 \mathrm{~m} \mathrm{~s}^{-1}$, and the correlation is $r=$ 0.75 (Table 1). Note that $c$ and $\bar{U}_{D}$ are independently estimated and that the small bias is not due to fitting. Furthermore, these error statistics are improved relative to using $g^{\prime}$ and $\delta$ at each mooring. That the $c$ variation is consistent with $\sqrt{D}$, using the mooring averaged $g^{\prime}$ and $\delta \approx 1 / 2$, further implies a "saturated" bore at most mooring locations (B2021b). Note, that although 
TABLE 1. Bore speed parameterizations error metrics: bias $\overline{c-U_{i}}$, RMSE $\overline{\left(c-U_{i}\right)^{2}}$, and correlation coefficient $r$ for the gravity current parameterization $U(1)$ and the saturated parameterization $\bar{U}_{D}(8)$. Statistics are averages over all (except $100 \mathrm{~m}$ ) moorings.

\begin{tabular}{ccc}
\hline \hline \multicolumn{1}{c}{ Error metric } & $U=F_{h} \sqrt{g^{\prime} h}$ & $\bar{U}_{D}=\bar{F}_{h}\left(1-\bar{F}_{h}^{2}\right)^{1 / 2} \sqrt{g^{\prime}} D$ \\
\hline Bias,$\overline{c-U_{i}}\left(\mathrm{~m} \mathrm{~s}^{-1}\right)$ & 0.010 & 0.000 \\
RMSE, $\overline{\left(c-U_{i}\right)^{2}}\left(\mathrm{~m} \mathrm{~s}^{-1}\right)$ & 0.038 & 0.033 \\
Correlation, $r$ & 0.65 & 0.75 \\
\hline
\end{tabular}

we are testing the scaling, a general functional best fit of $c \sim D^{\gamma}$ that goes through zero has best-fit $\gamma=0.62$, very close to the scaling value of $1 / 2$. We therefore consider (8) to represent the saturated gravity current parameterization.

\section{e. Bore peak kinetic energy and kinetic energy flux}

Here, the peak kinetic energy and kinetic energy flux at the nose of this single bore event are estimated assuming the flow is a two-layer gravity current. We only consider the kinetic energy at the nose of the bore, as the potential energy of the bore depends on the background buoyancy (stratification) that is not well constrained. Furthermore, the potential energy of a gravity current depends on flow and stratification details away from the nose of the gravity current (e.g., Shin et al. 2004). Thus, we neglect potential energy in this analysis. At each mooring, the peak bore kinetic energy just behind the gravity current nose can be expressed in terms of the observed propagation speed $c$ and the fractional bore depth $\delta$,

$$
K_{E}=\frac{1}{2} \rho_{0} c^{2} D\left(\frac{\delta}{1-\delta}\right),
$$

as fluid velocity behind the gravity current nose is $c$ and the lower-layer velocity is $-\delta c /(1-\delta)$ by continuity. Recall that the observed $c$ in this expression is estimated independently from $\delta$ and is based on the speed map (Fig. 4). At each mooring, the peak bore kinetic energy flux at the nose is then

$$
\mathcal{F}_{K}=c K_{E}=\frac{1}{2} \rho_{0} c^{3} D\left(\frac{\delta}{1-\delta}\right) .
$$

Averaging over the moorings, the mean bore peak kinetic energy $\bar{K}_{E}$ and mean bore peak energy flux $\overline{\mathcal{F}}_{K}$ can be written in terms of only the depth $D$ assuming the bore propagation speed is given by the saturated gravity current scaling $c=\bar{U}_{D}$ (8). Assuming saturation, using the mean reduced gravity $\bar{g}^{\prime}$ and the mean fractional depth $\bar{\delta}$, the saturated bore peak kinetic energy at the nose is

$$
\bar{K}_{E}=\frac{1}{2} \rho_{0} \overline{g^{\prime}} \bar{\delta}^{2} D^{2},
$$

and the saturated kinetic energy flux is

$$
\overline{\mathcal{F}}_{K}=\frac{1}{2} \rho_{0} \bar{g}^{3 / 2} \bar{\delta}^{5 / 2}(1-\bar{\delta})^{1 / 2} D^{5 / 2}
$$

These equations represent the peak kinetic energy energetics of a single bore and have the same $D$ dependence as the parameterizations in $\mathrm{B} 2021 \mathrm{~b}$.

The peak bore kinetic energy $K_{E}$ at each mooring decreases in shallower depths (colored dots Fig. 8a). The Oceano region has the smallest $\delta$ and $g^{\prime}$ (Fig. 5) leading to the smallest $K_{E}$ relative to $\mathrm{Pt}$. Sal and Vandenberg regions (colored dots in Fig. 7c). This is consistent with the regional alongshore variation in internal tide energetics in $9 \mathrm{~m}$ water depth over 1.5 months (Feddersen et al. 2020). The individual mooring peak $K_{E}$ generally follows the saturated bore peak kinetic
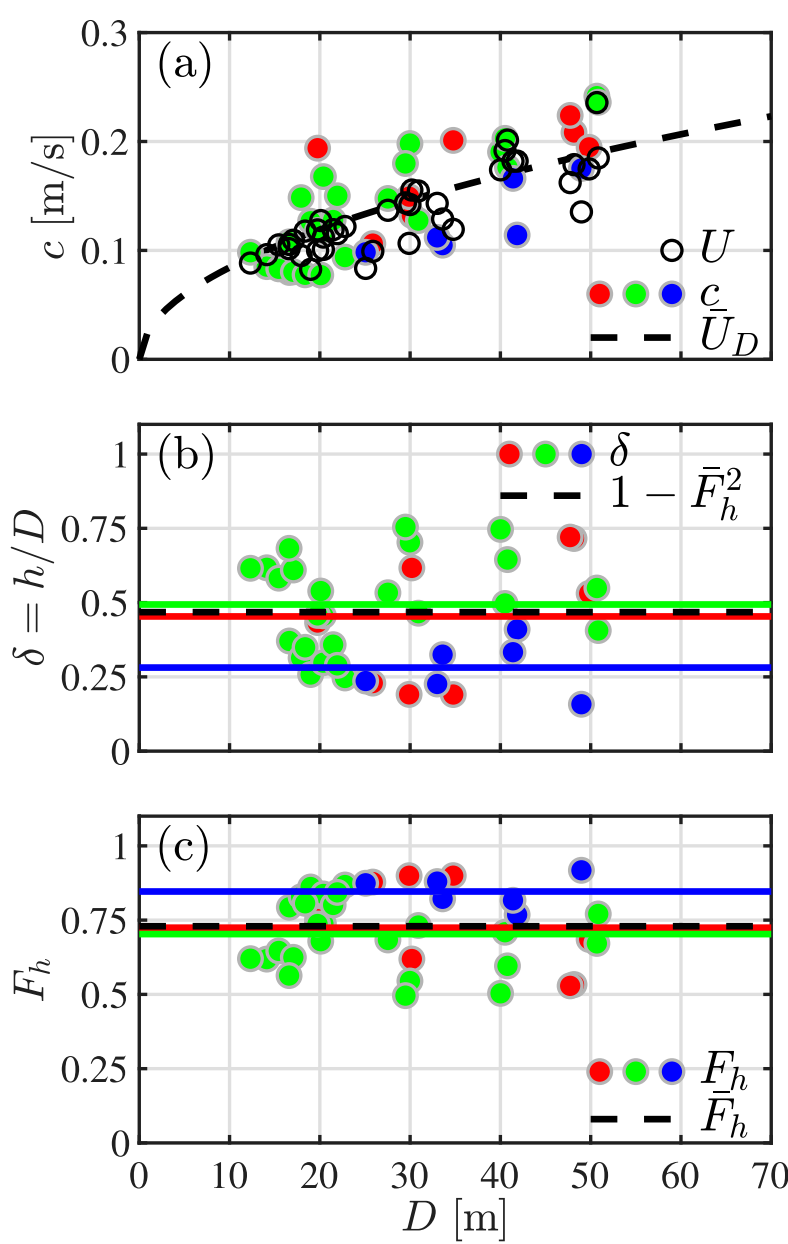

FIG. 7. (a) Estimated bore speed $c$ (7) and gravity current speed $U(1)$, (b) fractional bore thickness $\delta=h / D$, and (c) Froude number $F_{h}$ vs water depth $D$. In (a), colored dots are $c$, open circles are $U$ (1), and dashed black curve is the saturated gravity current scaling $\bar{U}_{D}(8)$. In (b) and (c) horizontal colored lines are averages of the corresponding colored dots. In (b) and (c), the dashed black line is $1-\bar{F}_{h}^{2}$ and $\bar{F}_{h}$, respectively. Regions indicated by dot color: Vandenberg $(y<-2 \mathrm{~km}$, red), Pt. Sal $(-2<y<7.5 \mathrm{~km}$, green), and Oceano $(y>7.5 \mathrm{~km}$, blue $)$. 
energy scaling of $\bar{K}_{E} \sim D^{2}$ (11) using $\bar{\delta}=1 / 2$ and $\overline{g^{\prime}}$ (cf. dots with black line, Fig. 8a), although scatter around the scaling is present. Similarly, the individual moorings' peak energy flux $\mathcal{F}_{K}$ generally follow the saturated bore peak kinetic energy flux scaling $\overline{\mathcal{F}}_{K} \sim D^{5 / 2}$ (cf. dots with black line Fig. 8), although there is scatter around the scaling. As with the result that $c$ can be largely represented by $\bar{U}_{D}$ scaling as $\sim D^{1 / 2}$ (section $4 \mathrm{~d}$ ), the energetics results reinforce the interpretation of this internal bore as a saturated gravity current propagating across the shelf, particularly in the Pt. Sal region.

Internal bore energetics have been previously calculated in a variety of coastal settings (e.g., Duda and Rainville 2008; St. Laurent 2008; Shroyer et al. 2010a). The peak bore energy calculated here differs from the energy calculated in M2020a, M2020b, and B2021b from the same dataset. In M2020a and M2020b, the depth-averaged kinetic energy time series is calculated directly from ISDE bandpassed (3 min-16h) ADCP velocities. In B2021b, kinetic energy is not considered and the analysis uses the time-average available potential energy. Thus, differences in including potential energy and averaging, make direct comparison challenging. However, the bore peak $K_{E} \approx 1500 \mathrm{~J} \mathrm{~m}^{-2}$ in 50 -m water depth here are comparable (once depth-normalized) to the bore-associated maximum instantaneous values of the bandpassed depth-averaged kinetic energy of $30 \mathrm{~J} \mathrm{~m}^{-3}$ in $50 \mathrm{~m}$ (M2020b). The time-averaged depth-integrated kinetic energy in M2020b follows a $\sim D^{2}$. scaling, implying average isotherm variation a constant fraction of the water depth (i.e., constant $\delta$ ) and consistent with the saturated gravity current peak energetics (11). The cross-shelf decay of the bore energy flux off of Pt. Sal in summer 2015 (C2018) is also consistent with the $\sim D^{5 / 2}$ (12) scaling. The parameterized energy and energy flux scalings (11) and (12) have different prefactors as B2021b due to differences in averaging and using available potential energy instead of kinetic energy. These expressions (11) and (12) are similar to the surfzone breaking wave generated turbulence literature (e.g., Feddersen and Trowbridge 2005; Feddersen 2012), with $g^{\prime}$ replaced by $g$. In both the surfzone and internal surfzone, the energy flux divergence $d \overline{\mathcal{F}}_{K} / d x$ represents a source of turbulence. Both observations of surfzone turbulent dissipation rate (Feddersen 2012) and the inner-shelf dissipation rate (B2021a) scale with saturated $d \overline{\mathcal{F}}_{K} / d x \sim D^{3 / 2}$ scaling.

\section{Discussion}

\section{a. Comparison to previous internal bore speed parameterizations}

The bore analyzed here is similar in amplitude (Fig. 2) and has a spatially variable speed within the speed range typical of the region (C2018; M2020a), suggesting this bore is representative of bores in the region. For example, in the $\mathrm{Pt}$. Sal region in 30-50 m, C2018 bore speeds (Fig. 9 in C2018) and bore speeds presented here, $U \sim 0.2 \mathrm{~m} \mathrm{~s}^{-1}$ (Fig. 7), are similar. Moreover, in 40-50-m depth in the Oceano region, M2020a bore speeds (Fig. 13 in M2020a) and bore speeds presented here, $U \approx 0.15 \mathrm{~m} \mathrm{~s}^{-1}$, are similar. Previous analysis (C2018; M2020a, M2020b) of bores in this area compared observed
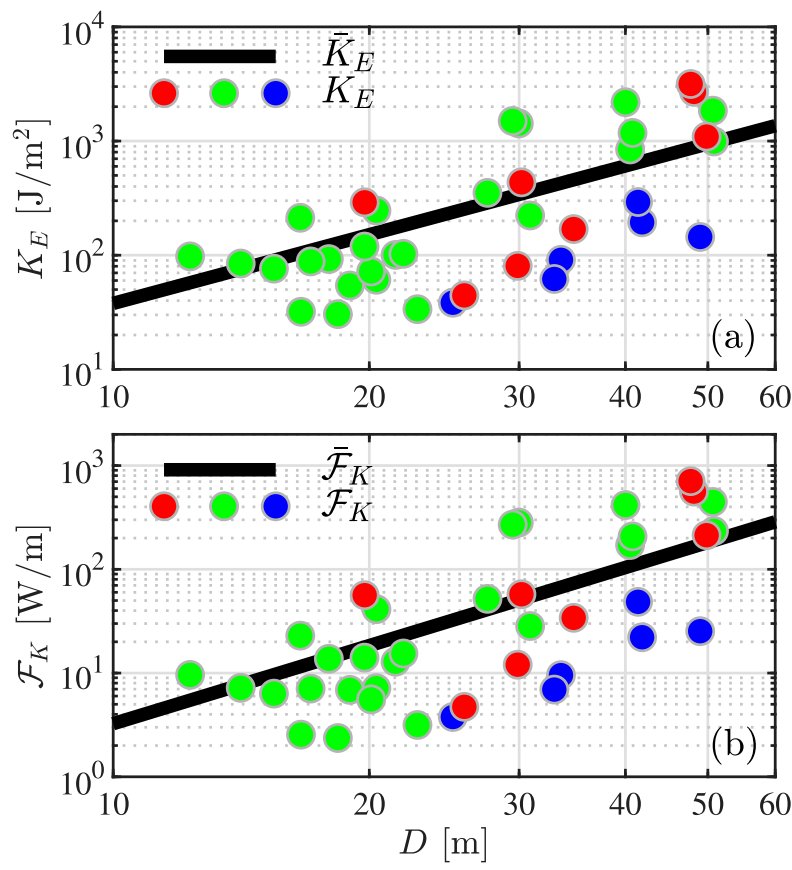

FIG. 8. (a) Estimated bore kinetic energy $K_{E}$ (9) and (b) estimated kinetic energy flux $\mathcal{F}_{K}(10)$ vs total depth $D$. In (a) and (b), colored dots represent individual moorings, and the black line is the parameterized saturated $(\bar{\delta}=1 / 2) \bar{K}_{E}$ and $\overline{\mathcal{F}}$, respectively. Regions are indicated by color: Vandenberg $(y<-2 \mathrm{~km}$, red), Pt. Sal $(-2<y<$ $7.5 \mathrm{~km}$, green $)$, and Oceano $(y>7.5 \mathrm{~km}$, blue).

bore speeds to internal wave speeds. In M2020a estimated bore speeds were compared to speeds obtained by solving the linear eigenproblem for the mode-1 (fastest) internal wave $c_{0}$,

$$
c_{0}^{2} \phi_{z z}=-N^{2}(z) \phi
$$

with $d \phi / d z=0$ at the surface and bottom and $N^{2}(z)$ is the squared buoyancy frequency based on a "sorted" density profile over two $\mathrm{M}_{2}$ periods (M2020a) or a "pre-arrival" (0.5-h average prior to bore arrival, M2020a) density. In the Oceano region over 3 months in fall 2017, the observed bore speeds generally compared well to both the prearrival and sorted density profiles linear wave speeds $c_{0}$ which generally followed the low-frequency (subtidal) varying stratification (M2020a). Wave speeds estimated with (13) using subtidal stratification, and including rotation and a $\mathrm{KdV}$ adjustment, reasonably followed observed bore speeds near Pt. Sal during summer 2015, but were unable to match the fastest bores (C2018).

Here, the speed of the strongly nonlinear (large $\delta$ ) bore front is consistent with a (implicitly nonlinear) gravity current. We investigate the applicability of linear speeds to this bore by calculating $c_{0}$ using (13). Here, the stratification is $N^{2}(z)=g \alpha \rho_{0}^{-1} d \bar{T}(z) / d z$ where $\alpha$ is the thermal expansion coefficient and $d \bar{T} / d z$ represents a time average. As $c_{0}$ is sensitive to how the background stratification is calculated (M2020a), two different time averages are used to estimate $N^{2}$. First, analogous to M2020a, a "prebore" stratification $N^{2}$ is estimated using a 4 -h time average from 1 to $5 \mathrm{~h}$ before bore 
arrival $\left(t_{B}\right)$ resulting in a prebore linear wave speed $c_{04}$. The 4-h average provides increases stability in stratification estimate and starting the average $1 \mathrm{~h}$ prior to $t_{B}$ ensures that bore water does not contaminate the estimate. Thus, this prebore $c_{04}$ differs from the M2020a prebore speed. Second, an 8-h time average centered on the $t_{B}$ is used for $N^{2}$ resulting in the centered linear wave speed $c_{08}$. Note that the $c_{08}$ time average also differs from the subtidally averaged or sorted-density based $N^{2}$ of C2018 and M2020a.

The linear internal wave speeds $\left(c_{04}\right.$ and $\left.c_{08}\right)$ do not parameterize the observed bore speed $c$ as well as $U$ (Fig. 6b and Table 2). The low correlation $(r=0.35)$ between prebore $c_{04}$ and $c$ and the large positive bias of $\overline{c-c_{04}}=0.043 \mathrm{~m} \mathrm{~s}^{-1}$ (Fig. $6 \mathrm{~b}$ and Table 2) indicate that, in general, the prebore stratification (without near-surface warm water) is too weak as linear $c \sim N$. The prebore $c_{04}$ are noticeably weaker than observed speeds $c>$ $0.15 \mathrm{~m} \mathrm{~s}^{-1}$ in the Vandenberg and Pt. Sal regions (Fig. 6b). However, in the Oceano region, $c_{04}$ is similar to $c$ (blue dots Fig. 6b). The 8-h centered stratification speed $c_{08}$ better parameterizes $c$ than $c_{04}$ because including warm bore water in the averaging increases the stratification. However, the 8-h stratification is also too weak with bias $\overline{c-c_{08}}=0.021 \mathrm{~m} \mathrm{~s}^{-1}$ (Table 2). Adjusting the $c_{04}$ and $c_{08}$ speeds assuming $\mathrm{KdV}$ weak nonlinearity, similar to C2018, resulted in less bias but higher RMSE due to the increased scatter (not shown). A linear $c \sim D\left(\right.$ not $\left.D^{1 / 2}\right)$ relationship, with no constant offset to ensure $c=0$ for $D=0$, clearly would poorly describe the observed bore speed-depth relationship (Fig. 7a). All this suggests that interpreting this internal bore as a mode- 1 internal wave riding on the prebore stratification, or the 8 -h $( \pm 4 \mathrm{~h}) t_{B}$-centered stratification, is not appropriate.

The improved skill of the gravity current scaling $U$ (1) relative to the internal wave speeds suggests that interpreting this bore as a large-amplitude gravity current is more appropriate than interpreting it as a linear or weakly nonlinear internal wave via KdV or eKdV framework (e.g., Gerkema and Zimmerman 2008). This bore has large nondimensional bore amplitude $(\delta \approx 1 / 2)$ that is too large for linear theory to apply. Similarly, a linear or weakly nonlinear wave would have very small near-surface isotherm displacements, counter to the observations (Fig. 2). Based on the duration of bore passage at the moorings (Fig. 2), the bore is also many times $(>10 \times$ converting time widths with $c$ to lengths in Fig. 2) wider than the depth, implying this (long-wave) bore is nondispersive. A classic measure of wave nonlinearity is the maximum Eulerian fluid velocity to wave speed ratio $u_{e} / c$. In a weakly nonlinear wave $u_{e} / c$ should be small $(\sim 0.1)$ whereas for a gravity current $u_{e} / c=1$. Here, drifters were trapped in the bore front and advected with the bore front for $2 \mathrm{~km}$ (Figs. 1b,c), indicating $u_{e} / c=1$. In many of the bores observed by C2018 and M2020a, the bore $\delta$ is large approaching $1 / 2$, near-surface isotherms are displaced a large fraction of depth, and the observed $u_{e} / c$ is often near one. Large-amplitude (relative to water depth) internal bores with strong nonlinearity and nondispersive dynamics are inconsistent with weakly nonlinear and weakly dispersive $\mathrm{KdV}$ or eKdV theory. The weakness of $\mathrm{KdV}$ and $\mathrm{eKdV}$ theory when applied to internal bores has previously been discussed (e.g., Lamb and Yan 1996; Stastna and Peltier 2005), as large amplitudes are inconsistent with the linear eigenproblem
TABLE 2. Bore speed parameterizations error metrics: bias $\overline{c-U_{i}}$, RMSE $\overline{\left(c-U_{i}\right)^{2}}$, and correlation coefficient $r$ for the gravity current parameterization (repeated from column 2 of Table 1 for reference) and the linear [ $c_{08}$ and $c_{04}$, from Eq. (13)] internal wave speeds. Statistics are over all (except $100 \mathrm{~m}$ ) moorings.

\begin{tabular}{lcll}
\hline \hline \multicolumn{1}{c}{ Error metric } & $F_{h} \sqrt{g^{\prime} h}$ & \multicolumn{1}{c}{$c_{08}$} & \multicolumn{1}{c}{$c_{04}$} \\
\hline Bias,$\overline{c-U_{i}}\left(\mathrm{~m} \mathrm{~s}^{-1}\right)$ & 0.010 & 0.021 & 0.043 \\
RMSE, $\overline{\left(c-U_{i}\right)^{2}}\left(\mathrm{~m} \mathrm{~s}^{-1}\right)$ & 0.038 & 0.048 & 0.063 \\
Correlation, $r$ & 0.65 & 0.50 & 0.35 \\
\hline
\end{tabular}

(13) leading to the usage of a corresponding nonlinear [DubreilJacotin-Long (DJL)] eigenproblem (e.g., Lamb and Wan 1998). Indeed Stastna and Peltier (2005) argue that weakly nonlinear $(\mathrm{KdV}$ and $\mathrm{eKdV})$ is best used as a qualitative tool for largeamplitude internal disturbances.

So why do the linear or $\mathrm{KdV}$-based bore speed estimates using filtered or sorted density (C2018a; M2020a) work as well as they do? A gravity current fundamentally depends on horizontal stratification of bore and prebore water, thus, $g^{\prime}$ is based on a horizontal density difference. A mode- 1 internal wave fundamentally depends on vertical stratification or in a two layer system $g^{\prime}$ is based on the vertical difference. The improved skill of $c_{08}$ relative to $c_{04}$ is likely due to the bore horizontal stratification $(\partial \rho / \partial x)$ being aliased into larger vertical stratification $(\partial \rho / \partial z)$ through the centered 8 -h average, and similarly for subtidally filtered or sorted-density stratifications. This can be made explicit for constant horizontal density difference $\Delta \rho$ aliased to vertical stratification. Then $N^{2} \sim \Delta \rho / D$ and $c=N D / \pi$ such that $c \sim(\Delta \rho)^{1 / 2} D^{1 / 2}$ as with the gravity current scaling. Thus, by aliasing the horizontal stratification to vertical stratification, via time averaging or density sorting, one can obtain reasonable bore speeds using linear or weakly nonlinear theory even though these dynamics may not be the most applicable to the internal bore.

\section{b. Interpretation as a two-layer gravity current}

We have interpreted this internal bore in a two-layer gravity current framework context. Using the methods for estimating bore arrival time $t_{B}$, bore thickness $h$, and associated temperature difference $\Delta T$, the estimated bore speed $c$ (Fig. 4) is consistent with the two-layer gravity current speeds $U$ (Fig. 6). Moreover, in the Pt. Sal region, the two-layer depth-normalized thickness $(\delta \approx 1 / 2)$ and energetics are consistent with saturation (B2021b). Although internal warm bores have been considered previously as gravity currents (Pineda 1994, 1999; Helfrich and Pineda 2003; Scotti and Pineda 2007), this work demonstrates that large-amplitude internal warm bores generated by the internal tide can be interpreted as a saturated gravity current over long propagation distances $(\approx 6 \mathrm{~km}$ in the cross shore). This gravity current interpretation likely applies to other warm bores with large isotherm displacements $(\delta \approx$ $1 / 2$ ) and Eulerian currents similar to the propagation speed. However, this two-layer gravity current interpretation has limits. For instance, gravity currents in the laboratory result from idealized lock releases with a flat bottom whereas the bore here is likely the product of the shoaling internal tide. 
Also inconsistent with two-layer theory, both the core of the bore and the fluid outside the bore is stratified, not homogeneous. Gravity currents of a homogeneous fluid propagating into a stratified ambient have been investigated in the laboratory (e.g., Maxworthy et al. 2002), and the speeds theoretically derived for uniform ambient stratification using steady hydraulic theory (Ungarish 2006), and for arbitrary ambient stratification using nonlinear long-wave (DJL) theory (White and Helfrich 2008). However, steady GC theory for a stratified gravity current core and a stratified ambient does not exist. Numerically simulated stratified internal bores, where the bore isotherm is in midwater column, have speeds consistent with both the solutions of the fully nonlinear long-wave DJL equation (e.g., White and Helfrich 2014) and the speed of a homogeneous gravity current propagating into a stratified ambient (White and Helfrich 2008). The effect of the stratified ambient on gravity current speeds is explicitly accounted for by the parameter $S=g^{\prime \prime} / g^{\prime}$, where $g^{\prime \prime}$ is the reduced gravity associated with the ambient and $g^{\prime}$ is the reduced gravity between the gravity current and the ambient (White and Helfrich 2008). Despite the stratified ambient in these studies, the functional form of the bore speed $\propto h^{1 / 2}$ is consistent with (1), suggesting that reducing this internal bore to two-layer gravity current is reasonable despite its stratified core and the stratified ambient. Here, the averaging used to calculate $\Delta T$ implicitly accounts for the effect of $S$ on propagation speed.

We have estimated the equivalent two-layer gravity current parameters (Shin et al. 2004), such as $h$ and $\Delta T$ in a consistent manner, implicitly accounting for stratification, which gives gravity current speeds in good agreement with observed bore speeds. The uncertainty of the parameter estimation is relatively small and even for shifted bore isotherm (e.g., $\eta_{B}, T_{B}$; section $3 a$ ), the gravity current speed estimates reproduce the observed bore speed. The agreement between observed bore speeds and gravity current parameterization is remarkable as an idealized steady-state gravity current is infinitely long and has uniform thickness behind the nose, whereas the internal bore here has finite cross-shore extent and a bore thickness that can vary after the nose (Fig. 2). Variable bore thickness can result from undular bores (e.g., C2018), or propagation into a stratified ambient that can give rise to a Kelvin-Helmholtz instability (White and Helfrich 2014). Here, very high-frequency internal waves riding on the bore (White and Helfrich 2008), would be smeared out by the 17.5-min low-pass filter. Nevertheless, for moorings where a bore was identified, the bore isotherm $\left(T_{B}\right)$ clearly is associated with very strong horizontal stratification at time $t_{B}$ and vertical stratification at the time when $h$ is chosen (Fig. 2). This indicates that a high stratification boundary exists between the bore fluid and the ambient, consistent with modeled internal bores (White and Helfrich 2014).

Gravity current speeds are often derived in an energy conserving context (e.g., Benjamin 1968). However, large-amplitude internal bores in the Pt. Sal region are highly dissipative (C2018) both in the bottom boundary layer (Becherer et al. 2020) and in the water column (Becherer et al. 2021a), with cross-shore energy loss scales of $3-5 \mathrm{~km}$ (C2018). Bore energy dissipation also induces mixing which would reduce the bore $\Delta T$. The large dissipation suggests that the internal bore would eventually reduce amplitude with $\Delta T$ becoming more linear and less dissipative (reduced breaking) if the bathymetry were constant. However, from the 50-m contour onshore, where this internal bore has large isotherm displacements (Figs. 2a,b) and is mostly saturated ( $\delta=1 / 2$, Fig. 5 in B2021b), propagation into shoaling bathymetry counteracts the effects of dissipation and the bore steepens between the 50- and 40-m isobath. Fully nonlinear high-resolution simulations of a single shoaling ISW from 3000- to 80-m depth showed that the leading ISW on the shelf (80-m depth) was a large-amplitude fully nonlinear soliton that resembled a square wave (Lamb and Warn-Varnas 2015). In Lamb and Warn-Varnas (2015), adding near-bed viscosity and diffusivity in their simulations, at peak values of $10^{-3} \mathrm{~m}^{2} \mathrm{~s}^{-1}$, which are realistic on the shelf (Suanda et al. 2017), led to a more triangular shaped bottom cold bores, analogous to what we observe here.

Note, the overall bathymetric slope varies regionally between Vandenberg, Pt. Sal, and Oceano (M2020b). The effect of gravity current shoaling on a slope is poorly understood and introduces a new nondimensional parameter the bathymetric slope $\beta$. Sutherland et al. (2013) performed lock-release twolayer laboratory experiments with $\delta=1 / 2$ and slopes one to two orders of magnitude larger than in the ISDE study region. The gravity current decelerated on the slope in a manner consistent with a cross-shore constant Froude number and local speed following (1). Although these laboratory slopes are far steeper than at the ISDE study region, our bore observations are qualitatively consistent with these sloping laboratory gravity current experiments (Sutherland et al. 2013).

Gravity currents are also modified by rotation (e.g., Griffiths 1986). In regions without boundaries gravity currents on flat bottoms initially propagate at speed independent of Coriolis parameter and arrest due to geostrophic adjustment after many inertial periods (e.g., Salinas et al. 2019). Here, the time from bore formation, in 50-100-m depth (B2021b), to arrival, in 10$15-\mathrm{m}$ depth, is about a single inertial period suggesting that bore propagation speed is influenced by Coriolis effects. This result is consistent with numerical modeling with and without rotation of a single ISW from the deep ocean to the shelf in the South China Sea (e.g., Lamb and Warn-Varnas 2015). For weakly nonlinear variable coefficient $\mathrm{KdV}$ type equations, the ISW breakup and subsequent packet evolution varies significantly with rotation, but the leading ISW speed and structure on the shelf were similar in runs with and without rotation (Grimshaw et al. 2014). Similarly, for fully nonlinear simulations, the leading ISW wave on the shelf propagated slightly slower with reduced amplitude due to the dispersive effects of rotation (Lamb and Warn-Varnas 2015).

\section{c. Internal bore contrast between Pt. Sal and Oceano regions}

This internal bore was saturated $(\delta \approx 1 / 2)$ in the Pt. Sal region. However, in the Oceano region, the bore $\delta$ was often substantially $<1 / 2$, particularly in depths $D<40 \mathrm{~m}$ (Fig. 7b). The bore $\Delta T$ was also somewhat weaker in Oceano than Pt. Sal region (Fig. 5c1). This resulted in slower Oceano bore speeds $c$ than in the Pt. Sal region (Fig. 7a) for the same water depth $D$. 
The internal bore was not observed in $D \leq 20$-m depth in the Oceano region and only at one of 4 moorings in $D=25-\mathrm{m}$ depth (Fig. 1a), suggesting that this internal bore had dissipated. This is broadly consistent with the regional along-coast variation in semidiurnal potential energy in $D \approx 10$-m depth (Feddersen et al. 2020) and 16-h high-passed kinetic energy (M2020b). In the Oceano region, Haney et al. (2021) examined the cross-shore breakup of an internal bore into a surface bolus that propagates as a gravity current and dissipates in $40-\mathrm{m}$ water depth. Here, we examine the differences in this internal bore behavior in the Oceano and Pt. Sal region.

Laboratory gravity current studies into a uniformly stratified ambient show that as $c / c_{0} \lesssim 1$, internal waves were generated at the front resulting in slowing and thinning of the front (e.g., Maxworthy et al. 2002). Numerical models of gravity currents propagating into a stratified ambient also clearly show this behavior (White and Helfrich 2008). At the Columbia River front, which acts as a gravity current, upstream radiation of internal waves has been observed (e.g., Nash and Moum 2005; Nash et al. 2009), with generation attributed to the river front speed decreasing below the linear long-wave speed $c_{0}$ from solving (13). The energy exchange from the gravity current to internal waves can be significant (Pan and Jay 2009). Using a three-layer model and theory, White and Helfrich (2012) show that substantial energy exchange can occur in the transcritical regime as $c / c_{0} \approx 1$.

The linear long-wave speed $c_{0}(13)$ of the ambient fluid is a key parameter that determines gravity current evolution and depends on stratification: for uniform stratification $c_{0}=N D / \pi$. During this October IOP time period, the overall stratification was weaker than the September IOP period, potentially leading to more likely supercritical $\left(c>c_{0}\right)$ bores in the October IOP. Over the ISDE experiment duration, the averaged stratification was much stronger in the Oceano region than Pt. Sal region in $D \leq 40$-m depth (Feddersen et al. 2020; B2021b), which would lead to larger Oceano $c_{0}$. The prebore stratification based $c_{04}$ did a poor job of parameterizing the bore speed $c$ everywhere but in the Oceano region (Fig. 6). Here, we further examine the geographical distribution of the ratio of bore speed to linear long-wave speed $c / c_{04}$ to understand the bore differences between Oceano and Pt. Sal regions.

Significant regional differences in $c / c_{04}$ for this bore are evident (Fig. 9), consistent with Fig. 6b. In 30-50-m depth, the ratio $c / c_{04}>1.7$ in the $\mathrm{Pt}$. Sal region whereas $c / c_{04}<1.4$ in the Oceano region. In $D \leq 30 \mathrm{~m}$, the ratio $c / c_{04}<1$ at all Oceano moorings where the bore was identified. In contrast, nearly all $D \leq 30 \mathrm{~m}$ Pt. Sal locations had $c / c_{04}>1$. Three locations near the tip of Pt. Sal have $c / c_{04}<1$ which we discuss in section $5 \mathrm{~d}$. The weak $c / c_{04}<1$ in the Oceano region suggests that this internal bore is subcritical and substantially losing energy in part to radiating internal waves. This would explain why the Oceano bore thickness becomes small and why the bore is not identified in shallower water (e.g., Fig. 3f). Thus, interpreting bores as gravity currents is more appropriate in regions where the bore is supercritical $\left(c / c_{04}>1\right)$, which is associated with the gravity current scaling (1) working well (Fig. 6a). These supercritical regions (i.e., Pt. Sal) typically have large isotherm displacements (i.e., $\delta \approx 1 / 2$ ) associated with bore saturation

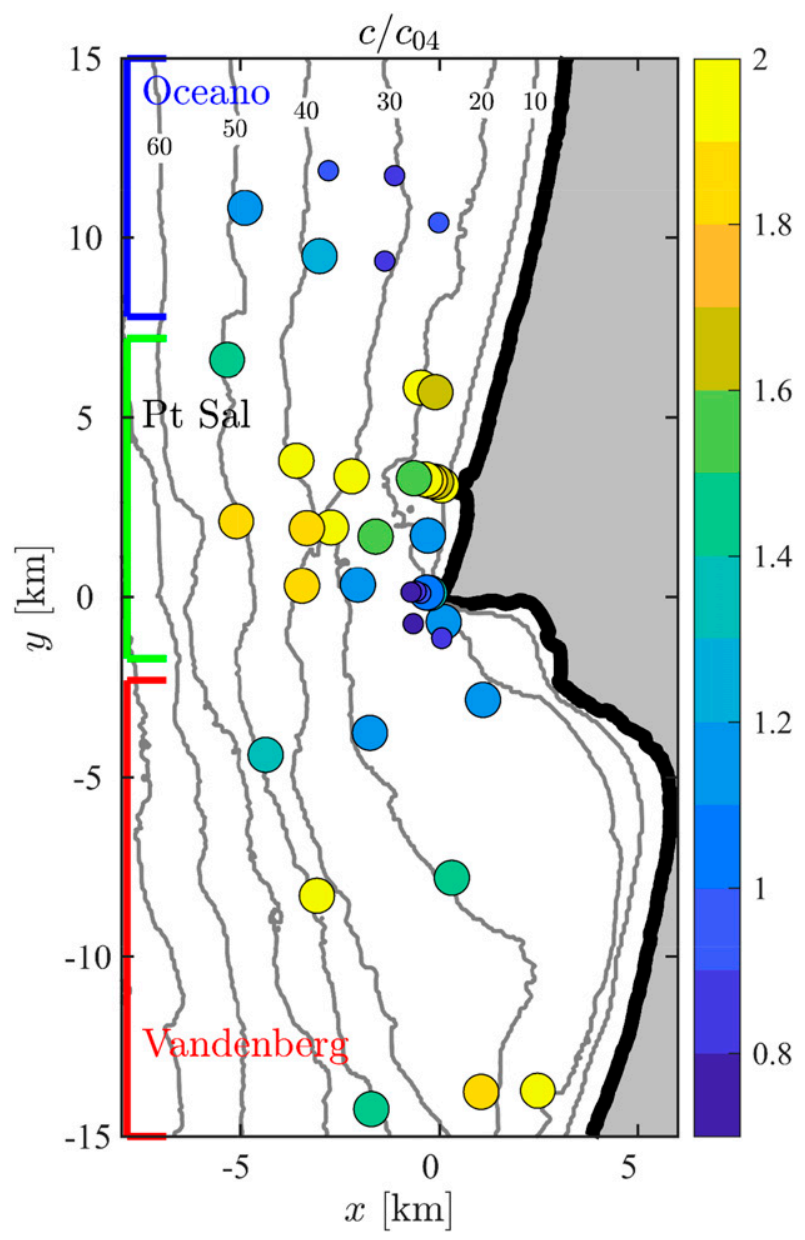

FIG. 9. The geographical distribution of the observed bore speed to the prebore linear wave speed $c / c_{04}$ (colors). Values $<1(>1)$ are small (large) circles. The Oceano, Pt. Sal, and Vandenberg regions are indicated, bathymetry is contoured at $10 \mathrm{~m}$ intervals, and the origin $(0,0)$ is the tip of Pt. Sal $\left(34.90304^{\circ} \mathrm{N}, 120.67207 \mathrm{~W}^{\circ}\right)$.

(B2021b). The Oceano region being generally subcritical is consistent with Oceano bore identification in 50-m depth (M2020b) and provides a reason why bores were more difficult to track onshore there (M2020a). This subcritical bore energy loss mechanism has also been used to explain the upstream release of a gravity current from an internal bore during the September IOP (Haney et al. 2021). This suggests that regional variations in stratification, low at Pt. Sal and elevated in the Oceano region (B2021b), can result in variable, over the region, bore evolution. A complete understanding of what causes these regional (over about $10 \mathrm{~km}$ ) stratification differences is lacking, although bore regional spatial variation may play a role (M2020b).

\section{d. The effect of Doppler shift by barotropic velocities}

Waves and gravity currents can have speeds Doppler shifted by depth-uniform mean currents. C2018 and M2020a corrected observed bore speeds for Doppler shift by removing the barotropic (depth-averaged) velocity in the propagation direction 
$U_{B}$, thus, $c \rightarrow c-U_{B}$. However, whether this improved the skill between observed bore speeds and linear wave speeds was not investigated. In our analysis, $c$ is well parameterized by a gravity current scaling without removing $U_{B}$. To investigate potential Doppler shift induced errors, $U_{B}$ was estimated for 22 moorings (in $<100$-m water depths) with collocated ADCP by depth- and time-averaging velocities for $t \in \hat{t}_{B} \pm 1 \mathrm{~h}$. The rootmean square $U_{B}$ is $0.031 \mathrm{~m} \mathrm{~s}^{-1}$ with maximum $\left|U_{B}\right|=0.076 \mathrm{~m} \mathrm{~s}^{-1}$. A Doppler shifted gravity current velocity $U_{B}+F_{h} \sqrt{g^{\prime} h}$ was then estimated to compare with the observed $c$ and gravity current scaling $F_{h} \sqrt{g^{\prime} h}$ using error statistics averaged over the 22 moorings with ADCPs (Table 3). As examining the effect of $U_{B}$ uses 22 locations instead of 39 locations, we examine first the non-Doppler shifted gravity current scaling $F_{h} \sqrt{g^{\prime} h}$ at these 22 locations (Table 3 ). The gravity current scaling predicts well the observed $c$ at the 22 locations (Table 3) with smaller bias, smaller RMSE, and moderately higher correlation than for the 39 locations in Table 2. Including the Doppler shift (i.e., $U_{B}$ ), results in slightly smaller bias but otherwise similar error statistics as without Doppler shift at these 22 locations (second and third columns in Table 3). Thus, overall Doppler shifted bore velocities are not a significant source of error between $c$ and the gravity current scaling.

Although barotropic velocities do not significantly affect the skill of the gravity current parameterization, there is evidence of localized current induced effects within $\approx 2 \mathrm{~km}$ southsouthwest of Pt. Sal. The visible-image identified surface front of the bore at 2330 UTC (Fig. 1c) is shore parallel north of Pt. Sal for $0<y<3 \mathrm{~km}$ but bends (or kinks) seaward about $1 \mathrm{~km}$ farther offshore just south of Pt. Sal $(y<0 \mathrm{~km})$. At 1800 UTC, the mapped bore location was just inshore of the 30$\mathrm{m}$ isobath, $\geq 2 \mathrm{~km}$ from shore, and relatively straight (Fig. 10a). At this time, near-bore barotropic velocity magnitudes were generally small $\left(<0.05 \mathrm{~m} \mathrm{~s}^{-1}\right.$, Fig. 10a) relative to the 0.15 to $0.2 \mathrm{~m} \mathrm{~s}^{-1}$ bore speed (Fig. 4b) and mostly oriented parallel to the bore, thus not inducing a Doppler shift. Just southsouthwest of Pt. Sal, the barotropic velocities were also weak at this time. Four hours later at 2200 UTC, the mapped bore is within $1 \mathrm{~km}$ of shore north of Pt. Sal $(y>0 \mathrm{~m})$, is kinked offshore just south of Pt. Sal $(-1<y<0 \mathrm{~km})$, and then bends back to the south-southeast for $y<-1 \mathrm{~km}$ (blue curve in Fig. 10). This mapped bore kink is consistent with the visual and SAR-observed bore (green curves in Fig. 10). However, the mapping smooths $\hat{t}_{B}$ in regions of strong gradients, such that the mapped bore at 2200 UTC and the visual bore at 2330 UTC nearly overlap just southwest of Pt. Sal. Thus, the mapped bore speeds (Fig. 4b) are biased high in this region within $1.5 \mathrm{~km}$ of Pt. Sal. The reduced bore speed in this region is likely due to relatively strong $\left(U_{b} \approx 0.1 \mathrm{~m} \mathrm{~s}^{-1}\right)$ tidally variable, offshore directed barotropic velocities south of Pt. Sal (Fig. 10b), where the bore kink and offshore directed velocities coincide. The small $c / c_{04}$ for three moorings off the tip of Pt. Sal (Fig. 9) is due to small $c$ induced by the barotropic velocity Doppler shift in this localized area. The barotropic currents potentially responsible for slowing the bore just southwest of Pt. Sal have significant diurnal and semidiurnal variability with zonal barotropic velocity $u_{B}$ that is approximately out of phase with the barotropic tide (Fig. 10c), consistent with tidal flow
TABLE 3. Bore speed parameterizations error metrics: bias $\overline{c-U_{i}}$, RMSE $\overline{\left(c-U_{i}\right)^{1 / 2}}$, and correlation coefficient $r$ for the 22 mooring locations with an ADCP. The second column is for the gravity current parameterization $F_{h} \sqrt{g^{\prime} h}$ (1) with statistics calculated at 22 locations in contrast to Table 2 with 39 locations. The third column has gravity current speed corrected for the barotropic velocity Doppler shift $U_{B}+F_{h} \sqrt{g^{\prime} h}$.

\begin{tabular}{llc}
\hline \hline \multicolumn{1}{c}{ Error metric } & $F_{h} \sqrt{g^{\prime} h}$ & $U_{B}+F_{h} \sqrt{g^{\prime} h}$ \\
\hline Bias,$\overline{c-U_{i}}\left(\mathrm{~m} \mathrm{~s}^{-1}\right)$ & 0.007 & 0.004 \\
RMSE, $\overline{\left(c-U_{i}\right)^{1 / 2}}\left(\mathrm{~m} \mathrm{~s}^{-1}\right)$ & 0.032 & 0.030 \\
Correlation, $r$ & 0.75 & 0.69 \\
\hline
\end{tabular}

observations near Pt. Sal (Kovatch et al. 2021). Thus, although overall the effect of the barotropic velocity Doppler shift on bore propagation is minimal, in the region just southwest of Pt. Sal, it could be significant indicating and the gravity current parameterization (1) will perform poorly in such regions. As subtidal and tidal depth-averaged flow past Pt. Sal is complex with significant vorticity generation, internal bores incident at different tidal phases may experience varying degrees of Doppler shift which could vary north to south of Pt. Sal. For example, X-band radar and in situ observations of an internal bore on 19 September 2017 reveal a slow bulge northwest of Pt. Sal (M2020b), which may be influenced by the barotropic current. Moreover, the speed of other bores in the Vandenberg region, also derived from by $\mathrm{X}$-band radar, show significant small-spatial-scale variability $[O(1) \mathrm{km}$; Celona et al. 2021] that may be linked to barotropic current effects. The effect of these depth-averaged flows on internal bore propagation and dissipation is not well understood.

\section{Summary}

As part of the 2017 Inner Shelf Dynamics Experiment conducted off the central coast of California near Pt. Sal, a single large-amplitude internal bore was observed on 10 October 2017. The bore was tracked from 100- to 10 -m depths (across $10 \mathrm{~km}$ in the cross shore) and along $30 \mathrm{~km}$ of coastline and is studied from the perspective of an idealized two-layer gravity current. The bore was observed by a number of instruments including remotely sensed SAR and visible imagery obtained from an airplane system, satellite SAR imagery, 39 in situ moorings, ship surveys, and drifters. Methods were developed to estimate bore arrival time $t_{B}$, bore thickness $h$, and temperature difference $\Delta T$ between bore and prebore water, which determines the reduced gravity $g^{\prime}$. A high-resolution arrival time map was derived from the instrument arrival times using a smoothing spline technique. Observed bore speeds $c$ and directions $\theta$ were determined from the arrival time map. From $h, g^{\prime}$ and the local depth $D$, the gravity current speeds $U=(1-h / D)^{1 / 2}\left(g^{\prime} h\right)^{1 / 2}$ were calculated.

The speed of this bore varied in the alongshore and decreased as the bore approached shore with speeds approximately $0.25 \mathrm{~m} \mathrm{~s}^{-1}$ in 50 -m depths and $<0.1 \mathrm{~m} \mathrm{~s}^{-1}$ in 10 -m depth. The fractional bore depth $h / D$, ranged from 0.16 to 0.75 although there is regional alongshore variation. On average, bore thickness was $1 / 2$ the water depth suggesting saturation. Estimated gravity current speeds reproduced the observed 

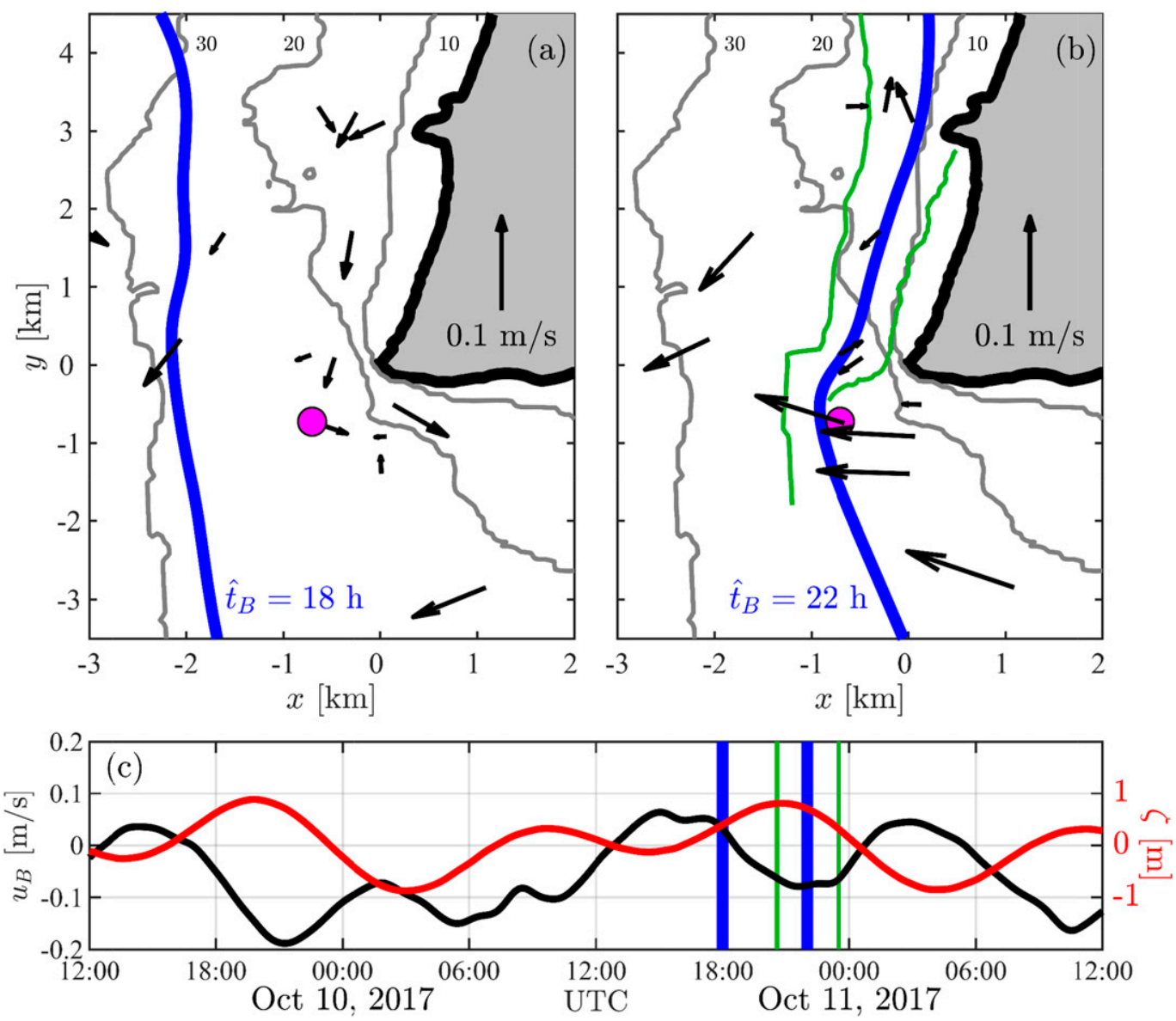

FIG. 10. (a),(b) Barotropic (depth-averaged) velocity vectors at the ADCPs near the tip of Pt. Sal at 1800 and 2200 UTC, respectively. A reference vector showing a velocity of $0.1 \mathrm{~m} \mathrm{~s}^{-1}$ is shown in (a) and (b). The mapped bore position at these times is indicated by the thick blue curve. i.e., $\hat{t}_{B}=1800$ and 2200 UTC in (a) and (b) respectively. In (b), the bore position from images at 2030 and 2330 UTC is indicated by thin green lines. Gray curves are the 10-, 20-, and 30-m isobaths. (c) The east-west component of the barotropic velocity $u_{B}$ (black, left axis) and tidal elevation $\zeta$ (red, right axis) vs time for the ADCP indicated by the magenta dot in (a) and (b). Times corresponding to the bore positions in (a) and (b) are indicated in (c) as vertical blue lines and image times are indicated as vertical green lines. In (a) and (b), the origin $(0,0)$ is the tip of Pt. Sal $\left(34.90304^{\circ} \mathrm{N}, 120.67207^{\circ} \mathrm{W}\right)$.

bore speeds with low bias and RMSE. Observed speeds compared slightly better to a saturated gravity current scaling $\bar{U}_{D}=(1 / 2)\left(\overline{g^{\prime}} D\right)^{1 / 2}$ that depends only on $D$ and the mean reduced gravity $\overline{g^{\prime}}$ than to the gravity current scaling that depends on the local gravity current thickness $h$ and local $g^{\prime}$. Overall, bore energetics have water depth dependence of a saturated gravity current scaling, which have the same depth dependence as surfzone energetics with the same formulations except for different prefactors and with $g^{\prime}$ for the internal bore instead of $g$ for a surfzone bore. Thus, this bore is the internal wave analog to a surfzone surface gravity bore. Observed speed of this bore compared better to gravity current speeds than linear internal wave speeds based on stratification. Accounting for Doppler shifting by barotropic velocities did not improve the relationship between $c$ and $U$, however, just southwest of Pt. Sal the bore slows consistent with Doppler shifting. The Oceano region's stronger prebore stratification result in subcritical bore propagation potentially explaining why the internal bore was less energetic and often could not be identified at some of the Oceano region moorings. The internal wave energy flux at the greater Pt. Sal region is particularly energetic (Kumar et al. 2019) and internal bores are often observed to be saturated (B2021a,b). In summary, this work shows that a saturated gravity current interpretation applies to a large-amplitude internal warm bore generated by the internal tide over long propagation distances ( $\approx 6 \mathrm{~km}$ in the cross shore). This suggests that other warm bores with large isotherm displacements $(\delta \approx 1 / 2)$, and Eulerian currents similar to the bore propagation speed, are also likely to be well interpreted as a gravity current. As such, interpreting other internal bores in this region (and other regions more generally) as a (strongly nonlinear) gravity current should be investigated further to determine the degree to which a gravity current interpretation applies to internal bores more generally.

Acknowledgments. This paper is dedicated to two dear colleagues who left us in 2020 and 2021: Sean Haney, who taught 
us so much about stratified bore dynamics, and Nirnimesh Kumar, who led our collective ISDE efforts. They will be sorely missed. This work was sponsored by the U.S. Office of Naval Research (ONR) in an ONR Departmental Research Initiative (DRI), Inner-Shelf Dynamics Experiment (ISDE). We thank Dr. Reginald Beach for supporting all the initiatives undertaken as a part of this project. We thank Jennifer MacKinnon for numerous helpful and stimulating discussions that improved this work. The authors also thank the reviewer that provided many comments and suggestions that resulted in a better manuscript. The satellite SAR image used here (Fig. 1a) is copyrighted: CDLR e.V. 2017. Distribution Airbus Defence and Space GmbH. Downlinked and processed by CSTARS under Airbus Defence and Space license. Observations are available in the Inner Shelf data repository hosted by UC San Diego Library (full dataset: https:/doi.org/10.6075/ J0WD3Z3Q, airborne data: https://doi.org/10.6075/J0C24TZJ). The MATLAB function RegularizeData3D.m performs the $\hat{t}_{B}$ mapping (https://www.mathworks.com/matlabcentral/fileexchange/46223regularizedata3d).

\section{REFERENCES}

Aghsaee, P., L. Boegman, and K. G. Lamb, 2010: Breaking of shoaling internal solitary waves. J. Fluid Mech., 659, 289-317, https://doi.org/10.1017/S002211201000248X.

Alpers, W., 1985: Theory of radar imaging of internal waves. Nature, 314, 245-247, https://doi.org/10.1038/314245a0.

Becherer, J., J. N. Moum, J. A. Colosi, J. A. Lerczak, and J. M. McSweeney, 2020: Turbulence asymmetries in bottom boundary layer velocity pulses associated with onshore-propagating nonlinear internal waves. J. Phys. Oceanogr., 50, 2373-2391, https://doi.org/10.1175/JPO-D-19-0178.1.

— the inner continental shelf Part I: Observations. J. Phys. Oceanogr., 51, 2553-2563, https://doi.org/10.1175/JPO-D-200264.1.

— inner continental shelf Part II: Parameterization. J. Phys. Oceanogr., 51, 2565-2582, https://doi.org/10.1175/JPO-D-210047.1.

Benjamin, T. B., 1968: Gravity currents and related phenomena. J. Fluid Mech., 31, 209-248, https://doi.org/10.1017/S0022112068000133.

Boegman, L., and M. Stastna, 2019: Sediment resuspension and transport by internal solitary waves. Annu. Rev. Fluid Mech., 51, 129-154, https://doi.org/10.1146/annurev-fluid-122316-045049.

Bourgault, D., and D. E. Kelley, 2003: Wave-induced boundary mixing in a partially mixed estuary. J. Mar. Res., 61, 553-576, https://doi.org/10.1357/002224003771815954.

Celona, S., S. T. Merrifield, T. de Paolo, N. Kaslan, T. Cook, E. J. Terrill, and J. A. Colosi, 2021: Automated detection, classification, and tracking of internal wave signatures using X-band radar in the inner shelf. J. Atmos. Oceanic Technol., 38, 789803, https://doi.org/10.1175/JTECH-D-20-0129.1.

Colosi, J. A., N. Kumar, S. H. Suanda, T. M. Freismuth, and J. H. MacMahan, 2018: Statistics of internal tide bores and internal solitary waves observed on the inner continental shelf off Point Sal, California. J. Phys. Oceanogr., 48, 123-143, https:// doi.org/10.1175/JPO-D-17-0045.1.

Coutino, A., and M. Stastna, 2017: The fully nonlinear stratified geostrophic adjustment problem. Nonlinear Processes Geophys., 24, 61-75, https://doi.org/10.5194/npg-24-61-2017. da Silva, J. C. B., and K. R. Helfrich, 2008: Synthetic aperture radar observations of resonantly generated internal solitary waves at Race Point Channel (Cape Cod). J. Geophys. Res., 113, C11016, https://doi.org/10.1029/2008JC005004.

Davis, R. E., 1985: Drifter observations of coastal surface currents during CODE: The method and descriptive view. J. Geophys. Res., 90, 4741-4755, https://doi.org/10.1029/JC090iC03p04741.

Duda, T. F., and L. Rainville, 2008: Diurnal and semidiurnal internal tide energy flux at a continental slope in the South China Sea. J. Geophys. Res., 113, C03025, https://doi.org/ 10.1029/2007JC004418.

Farquharson, G., H. Deng, Y. Goncharenko, and J. Mower, 2014: Dualbeam ATI SAR measurements of surface currents in the nearshore ocean. 2014 IEEE Geoscience and Remote Sensing Symp., Quebec City, QC, Institute of Electrical and Electronics Engineers, 26612664, https://doi.org/10.1109/IGARSS.2014.6947021.

Feddersen, F., 2012: Scaling surf zone turbulence. Geophys. Res. Lett., 39, L18613, https://doi.org/10.1029/2012GL052970.

_ , and J. H. Trowbridge, 2005: The effect of wave breaking on surf-zone turbulence and alongshore currents: A modeling study. J. Phys. Oceanogr., 35, 2187-2203, https://doi.org/ 10.1175/JPO2800.1.

—, J. H. MacMahan, T. M. Freismuth, M. K. Gough, and M. Kovatch, 2020: Inner-shelf vertical and alongshore temperature variability in the subtidal, diurnal, and semidiurnal bands along the central California coastline with headlands. J. Geophys. Res. Oceans, 125, e2019JC015347, https://doi.org/ 10.1029/2019JC015347.

Gerkema, T., and J. T. F. Zimmerman, 2008: An Introduction to internal waves: Lecture notes. Royal Netherlands Institute for Sea Research, 207 pp.

Griffiths, R. W., 1986: Gravity currents in rotating systems. Annu. Rev. Fluid Mech., 18, 59-89, https://doi.org/10.1146/ annurev.fl.18.010186.000423.

Grimshaw, R., E. Pelinovsky, T. Talipova, and A. Kurkin, 2004: Simulation of the transformation of internal solitary waves on oceanic shelves. J. Phys. Oceanogr., 34, 2774-2791, https:// doi.org/10.1175/JPO2652.1.

- C. Guo, K. Helfrich, and V. Vlasenko, 2014: Combined effect of rotation and topography on shoaling oceanic internal solitary waves. J. Phys. Oceanogr., 44, 1116-1132, https://doi.org/ 10.1175/JPO-D-13-0194.1.

Haney, S., and Coauthors, 2021: Lifecycle of a submesoscale front birthed from a nearshore internal bore. J. Phys. Oceanogr., 51, 3477-3493, https://doi.org/10.1175/JPO-D-21-0062.1.

Helfrich, K. R., and J. Pineda, 2003: Accumulation of particles in propagating fronts. Limnol. Oceanogr., 48, 1509-1520, https:// doi.org/10.4319/lo.2003.48.4.1509.

— Annu. Rev. Fluid Mech., 38, 395-425, https://doi.org/10.1146/ annurev.fluid.38.050304.092129.

— internal tide. J. Phys. Oceanogr., 38, 686-701, https://doi.org/ 10.1175/2007JPO3826.1.

Kovatch, M., F. Feddersen, D. Grimes, and J. MacMahan, 2021: Vorticity recirculation and asymmetric generation at a small headland with broadband currents. J. Geophys. Res. Oceans, 126, e2020JC016639, https://doi.org/10.1029/2020JC016639.

Kropfli, R. A., L. A. Ostrovski, T. P. Stanton, E. A. Skirta, A. N. Keane, and V. Irisov, 1999: Relationships between strong internal waves in the coastal zone and their radar and radiometric signatures. J. Geophys. Res., 104, 3133-3148, https:// doi.org/10.1029/98JC02549. 
Kumar, N., S. H. Suanda, J. A. Colosi, K. Haas, E. Di Lorenzo, A. J. Miller, and C. A. Edwards, 2019: Coastal semidiurnal internal tidal incoherence in the Santa Maria Basin, California: Observations and model simulations. J. Geophys. Res. Oceans, 124, 5158-5179, https://doi.org/10.1029/2018JC014891.

— , and Coauthors, 2021: The Inner-Shelf Dynamics Experiment. Bull. Amer. Meteor. Soc., 102, E1033-E1063, https://doi.org/ 10.1175/BAMS-D-19-0281.1.

Lamb, K. G., 2014: Internal wave breaking and dissipation mechanisms on the continental slope/shelf. Annu. Rev. Fluid Mech., 46, 231-254, https://doi.org/10.1146/annurev-fluid-011212-140701.

— Comparisons of a fully nonlinear numerical model with weakly nonlinear theory. J. Phys. Oceanogr., 26, 2712-2734, https:// doi.org/10.1175/1520-0485(1996)026<2712:TEOIWU > 2.0.CO;2.

_ for a continuously stratified fluid. Phys. Fluids, 10, 2061-2079, https://doi.org/10.1063/1.869721.

—_, and K. P. Wilkie, 2004: Conjugate flows for waves with trapped cores. Phys. Fluids, 16, 4685-4695, https://doi.org/ 10.1063/1.1811551.

— simulations of shoaling internal solitary waves at the ASIAEX site in the South China Sea. Nonlinear Processes Geophys., 22, 289-312, https://doi.org/10.5194/npg-22-289-2015.

Lentz, S. J., and K. R. Helfrich, 2002: Buoyant gravity currents along a sloping bottom in a rotating fluid. J. Fluid Mech., 464, 251-278, https://doi.org/10.1017/S0022112002008868.

Liu, A., S. Ramp, Y. Zhao, and T. Y. Tang, 2004: A case study of internal solitary wave propagation during ASIAEX 2001. IEEE J. Oceanic Eng., 29, 1144-1156, https://doi.org/10.1109/ JOE.2004.841392.

MacKinnon, J. A., and M. C. Gregg, 2003: Mixing on the latesummer New England shelf-Solibores, shear, and stratification. J. Phys. Oceanogr., 33, 1476-1492, https://doi.org/10.1175/ 1520-0485(2003)033<1476:MOTLNE>2.0.CO;2.

Maxworthy, T., J. Leilich, J. E. Simpson, and E. H. Meiburg, 2002: The propagation of a gravity current into a linearly stratified fluid. J. Fluid Mech., 453, 371-394, https://doi.org/10.1017/ S0022112001007054.

McSweeney, J. M., and Coauthors, 2020a: Observations of shoaling nonlinear internal bores across the central California inner shelf. J. Phys. Oceanogr., 50, 111-132, https://doi.org/10.1175/ JPO-D-19-0125.1.

— internal bores on the inner shelf. J. Phys. Oceanogr., 50, 29652981, https://doi.org/10.1175/JPO-D-20-0090.1.

— M. R. Fewings, J. A. Lerczak, and J. A. Barth, 2021: Tracking the northward propagation of a buoyant coastal plume after a regional wind relaxation event. J. Geophys. Res. Oceans, https://doi.org/10.1029/2021JC017720, in press.

Melton, C., L. Washburn, and C. Gotschalk, 2009: Wind relaxations and poleward flow events in a coastal upwelling system on the central California coast. J. Geophys. Res., 114, C11016, https:// doi.org/10.1029/2009JC005397.

Moum, J. N., J. M. Klymak, J. D. Nash, A. Perlin, and W. D. Smyth, 2007: Energy transport by nonlinear internal waves. J. Phys. Oceanogr., 37, 1968-1988, https://doi.org/10.1175/JPO3094.1.

Nash, J. D., and J. N. Moum, 2005: River plumes as a source of large-amplitude internal waves in the coastal ocean. Nature, 437, 400-403, https://doi.org/10.1038/nature03936.

_, L. F. Kilcher, and J. M. Moum, 2009: Structure and composition of a strongly stratified, tidally pulsed river plume.
J. Geophys. Res., 114, C00B12, https://doi.org/10.1029/ 2008JC005036.

Pan, J., and D. A. Jay, 2009: Dynamic characteristics and horizontal transports of internal solitons generated at the Columbia River plume front. Cont. Shelf Res., 29, 252-262, https:// doi.org/10.1016/j.csr.2008.01.002.

Pawlowicz, R., 2003: Quantitative visualization of geophysical flows using low-cost oblique digital time-lapse imaging. IEEE J. Oceanic Eng., 28, 699-710, https://doi.org/10.1109/JOE.2003.819310.

Pham, H. T., and S. Sarkar, 2018: Ageostrophic secondary circulation at a submesoscale front and the formation of gravity currents. J. Phys. Oceanogr., 48, 2507-2529, https://doi.org/ 10.1175/JPO-D-17-0271.1.

Pineda, J., 1994: Internal tidal bores in the nearshore: Warm-water fronts, seaward gravity currents and the onshore transport of neustonic larvae. J. Mar. Res., 52, 427-458, https://doi.org/ 10.1357/0022240943077046.

_ 1999: Circulation and larval distribution in internal tidal bore warm fronts. Limnol. Oceanogr., 44, 1400-1414, https://doi.org/ 10.4319/lo.1999.44.6.1400.

Ramos, R. J., B. Lund, and H. C. Graber, 2009: Determination of internal wave properties from X-band radar observations. Ocean Eng., 36, 1039-1047, https://doi.org/10.1016/ j.oceaneng.2009.07.004.

Raubenheimer, B., S. Elgar, and R. T. Guza, 1996: Wave transformation across the inner surf zone. J. Geophys. Res., 101, 25 589-25 597, https://doi.org/10.1029/96JC02433.

Reinsch, C., 1967: Smoothing by spline functions. Numer. Math., 10, 177-183, https://doi.org/10.1007/BF02162161.

Salinas, J. S., T. Bonometti, M. Ungarish, and M. I. Cantero, 2019: Rotating planar gravity currents at moderate Rossby numbers: Fully resolved simulations and shallow-water modelling. J. Fluid Mech., 867, 114-145, https://doi.org/10.1017/ jfm.2019.152.

Scotti, A., and J. Pineda, 2007: Plankton accumulation and transport in propagating nonlinear internal fronts. J. Mar. Res., 65 , 117-145, https://doi.org/10.1357/002224007780388702.

_ R. C. Beardsley, B. Butman, and J. Pineda, 2008: Shoaling of nonlinear internal waves in Massachusetts Bay. J. Geophys. Res., 113, C08031, https://doi.org/10.1029/2008JC004726.

Shi, F., C. C. Chickadel, T.-J. Hsu, J. T. Kirby, G. Farquharson, and G. Ma, 2017: High-resolution non-hydrostatic modeling of frontal features in the mouth of the Columbia River. Estuaries Coasts, 40, 296-309, https://doi.org/10.1007/s12237-016-0132-y.

Shin, J. O., S. B. Dalziel, and P. F. Linden, 2004: Gravity currents produced by lock exchange. J. Fluid Mech., 521, 1-34, https:// doi.org/10.1017/S002211200400165X.

Shroyer, E. L., J. N. Moum, and J. D. Nash, 2009: Observations of polarity reversal in shoaling nonlinear internal waves. J. Phys. Oceanogr., 39, 691-701, https://doi.org/10.1175/2008JPO3953.1.

$\_,-$, and 2010a: Energy transformations and dissipation of nonlinear internal waves over New Jersey's continental shelf. Nonlinear Processes Geophys., 17, 345-360, https:// doi.org/10.5194/npg-17-345-2010.

,$- \ldots$, and $\_, 2010 \mathrm{~b}$ : Vertical heat flux and lateral mass transport in nonlinear internal waves. Geophys. Res. Lett., 37, L08601, https://doi.org/10.1029/2010GL042715.

,-- , and 2011: Nonlinear internal waves over New Jersey's continental shelf. J. Geophys. Res., 116, C03022, https://doi.org/10.1029/2010JC006332.

Simonin, D., A. R. Tatnall, and I. S. Robinson, 2009: The automated detection and recognition of internal waves. Int. J. Remote Sens., 30, 4581-4598, https://doi.org/10.1080/01431160802621218. 
Simpson, J. E., 1997: Gravity Currents in the Environment and in the Laboratory. 2nd ed. Cambridge University Press, $262 \mathrm{pp}$.

Sinnett, G., F. Feddersen, A. J. Lucas, G. Pawlak, and E. Terrill, 2018: Observations of nonlinear internal wave run-up to the surfzone. J. Phys. Oceanogr., 48, 531-554, https://doi.org/ 10.1175/JPO-D-17-0210.1.

Spydell, M. S., F. Feddersen, and J. Macmahan, 2021: Relative dispersion on the inner shelf: Evidence of a Batchelor regime. J. Phys. Oceanogr., 51, 519-536, https://doi.org/10.1175/JPOD-20-0170.1.

Stastna, M., and W. R. Peltier, 2005: On the resonant generation of large-amplitude internal solitary and solitary-like waves. J. Fluid Mech., 543, 267-292, https://doi.org/10.1017/S002211200500652X.

St. Laurent, L., 2008: Turbulent dissipation on the margins of the South China Sea. Geophys. Res. Lett., 35, L23615, https:// doi.org/10.1029/2008GL035520.

Suanda, S. H., J. A. Barth, R. A. Holman, and J. Stanley, 2014: Shore-based video observations of nonlinear internal waves across the inner shelf. J. Atmos. Oceanic Technol., 31, 714-728, https://doi.org/10.1175/JTECH-D-13-00098.1.

_- and Coauthors, 2016: Wind relaxation and a coastal buoyant plume north of Pt. Conception, CA: Observations, simulations, and scalings. J. Geophys. Res. Oceans, 121, 7455-7475, https://doi.org/10.1002/2016JC011919.

_, F. Feddersen, and N. Kumar, 2017: The effect of barotropic and baroclinic tides on coastal stratification and mixing. J. Geophys. Res. Oceans, 122, $10156-10173$, https://doi.org/ 10.1002/2017JC013379.

Sutherland, B. R., D. Polet, and M. Campbell, 2013: Gravity currents shoaling on a slope. Phys. Fluids, 25, 086604, https:// doi.org/10.1063/1.4818440.

Thomas, J. A., J. A. Lerczak, and J. N. Moum, 2016: Horizontal variability of high-frequency nonlinear internal waves in Massachusetts Bay detected by an array of seafloor pressure sensors. J. Geophys. Res. Oceans, 121, 5587-5607, https:// doi.org/10.1002/2016JC011866.

Trossman, D. S., L. Thompson, and S. L. Hautala, 2011: Application of thin-plate splines in two dimensions to oceanographic tracer data. J. Phys. Oceanogr., 28, 1522-1538, https://doi.org/10.1175/ JTECH-D-10-05024.1.
Ungarish, M., 2006: On gravity currents in a linearly stratified ambient: A generalization of Benjamin's steady-state propagation results. J. Fluid Mech., 548, 49-68, https://doi.org/ 10.1017/S0022112005007421.

_ 2008: Energy balances and front speed conditions of two-layer models for gravity currents produced by lock release. Acta Mech., 201, 63-81, https://doi.org/10.1007/s00707-008-0073-z.

Vlasenko, V., and K. Hutter, 2002: Numerical experiments on the breaking of solitary internal waves over a slope-shelf topography. J. Phys. Oceanogr., 32, 1779-1793, https://doi.org/ 10.1175/1520-0485(2002)032<1779:NEOTBO > 2.0.CO;2.

Wahba, G., and J. Wendelberger, 1980: Some new mathematical methods for variational objective analysis using splines and cross validation. Mon. Wea. Rev., 108, 1122-1143, https://doi.org/ 10.1175/1520-0493(1980)108<1122:SNMMFV>2.0.CO;2.

Walter, R. K., C. B. Woodson, R. S. Arthur, O. B. Fringer, and S. G. Monismith, 2012: Nearshore internal bores and turbulent mixing in southern Monterey Bay. J. Geophys. Res., 117, C07017, https://doi.org/10.1029/2012JC008115.

Warner, S. J., R. M. Holmes, E. H. M. Hawkins, M. S. HoeckerMartínez, A. C. Savage, and J. N. Moum, 2018: Buoyant gravity currents released from tropical instability waves. J. Phys. Oceanogr., 48, 361-382, https://doi.org/10.1175/JPOD-17-0144.1.

White, B. L., and K. R. Helfrich, 2008: Gravity currents and internal waves in a stratified fluid. J. Fluid Mech., 616, 327-356, https://doi.org/10.1017/S0022112008003984.

$\longrightarrow$, and —, 2012: A general description of a gravity current front propagating in a two-layer stratified fluid. J. Fluid Mech., 711, 545-575, https://doi.org/10.1017/jfm.2012.409.

$\longrightarrow$, and - 2014: A model for internal bores in continuous stratification. J. Fluid Mech., 761, 282-304, https://doi.org/ 10.1017/jfm.2014.599.

Woodson, C. B., 2018: The Fate and Impact of Internal Waves in Nearshore Ecosystems. Annu. Rev. Mar. Sci., 10, 421-441, https://doi.org/10.1146/annurev-marine-121916-063619.

Zhang, S., M. H. Alford, and J. B. Mickett, 2015: Characteristics, generation, and mass transport of nonlinear internal waves on the Washington continental shelf. J. Geophys. Res. Oceans, 120, 741-758, https://doi.org/10.1002/2014JC010393. 